\title{
Microscopic Quantification of Oxygen Consumption across Cortical Layers
}

Abbreviated title: Laminar $\mathrm{CMRO}_{2}$ in cerebral cortex

Philipp Mächler ${ }^{1 \dagger *}$, Natalie Fomin-Thunemann ${ }^{1 *}$, Martin Thunemann1, Marte Julie Sætra ${ }^{3}$, Michèle Desjardins ${ }^{4}$, Kıvılcım Kılıç ${ }^{1}$ Ikbal Şencan ${ }^{5}$, Baoqiang Li5\#, Payam Saisan², Qun Cheng², Kimberly L. Weldy ${ }^{2}$, David A. Boas ${ }^{1}$, Richard B. Buxton ${ }^{6}$, Gaute T. Einevoll ${ }^{7,8}$, Anders M. Dale ${ }^{2,6}$, Sava Sakadžić $5 \S$, Anna Devor ${ }^{1,5 \S}$

${ }^{1}$ Department of Biomedical Engineering, Boston University, Boston, MA 02215, USA

${ }^{2}$ Department of Neurosciences, University of California San Diego, La Jolla, CA 92093, USA

${ }^{3}$ Department of Scientific Computing and Numerical Analysis, Simula Research Laboratory, N1325 Lysaker, Norway

${ }^{4}$ Département de physique, de génie physique et d'optique, Université Laval, Québec, QC G1V 0A6, Canada

${ }^{5}$ Athinoula A. Martinos Center for Biomedical Imaging, Department of Radiology, Harvard Medical School, Massachusetts General Hospital, Charlestown, MA 02129, USA

${ }^{6}$ Department of Radiology, University of California San Diego, La Jolla, CA 92093, USA

${ }^{7}$ Department of Physics, University of Oslo, 0316 Oslo, Norway

${ }^{8}$ Department of Physics, Norwegian University of Life Sciences, N-1432 Ås, Norway

*These authors equally contributed to this work.

Key words: 2-photon microscopy; $\mathrm{CMRO}_{2}$; phosphorescence; cerebral cortex; laminar

tPresent address: Department of Physics, University of California San Diego, La Jolla, CA 92093, USA 
\#Present address: Brain Cognition and Brain Disease Institute, Shenzhen Institute of Advanced

Technology, Chinese Academy of Sciences, Shenzhen Guangdong, 518055, China

$\S$ Corresponding authors:

Anna Devor

610 Commonwealth Ave

Boston, MA 02215

USA

Email: adevor@bu.edu
Sava Sakadzic

$14913^{\text {th }} \mathrm{St}$

Charlestown, MA 02129

USA

Acknowledgements: We dedicate this paper to the memory of Andrei Vinogradov, a pioneer of mitochondrial energetics. We gratefully acknowledge support from the NIH (BRAIN Initiative R01MH111359, $\quad$ BRAIN Initiative U19NS123717, R01DA050159, R01NS108472, K99MH120053) and Swiss National Science Foundation (P2ZHP3_181568). Phosphorescent probe Oxyphor 2P was provided by the resource "Oxygen imaging by phosphorescence quenching", supported by the grant U24 EB028941 from the National Institutes of Health, USA (directed by Dr. Sergei Vinogradov, University of Pennsylvania). 


\begin{abstract}
The cerebral cortex is organized in cortical layers that differ in their cellular density, composition, and wiring. Cortical laminar architecture is also readily revealed by staining for cytochrome oxidase - the last enzyme in the respiratory electron transport chain located in the inner mitochondrial membrane. It has been hypothesized that a high-density band of cytochrome oxidase in cortical layer IV reflects higher oxygen consumption under baseline (unstimulated) conditions. Here, we tested the above hypothesis using direct measurements of the partial pressure of $\mathrm{O}_{2}\left(\mathrm{pO}_{2}\right)$ in cortical tissue by means of 2-photon phosphorescence lifetime microscopy (2PLM). We revisited our previously developed method for extraction of the cerebral metabolic rate of $\mathrm{O}_{2}\left(\mathrm{CMRO}_{2}\right)$ based on 2-photon $\mathrm{pO}_{2}$ measurements around diving arterioles and applied this method to estimate baseline $\mathrm{CMRO}_{2}$ in awake mice across cortical layers. To our surprise, our results revealed a decrease in baseline $\mathrm{CMRO}_{2}$ from layer I to layer IV. This decrease of $\mathrm{CMRO}_{2}$ with cortical depth was paralleled by an increase in tissue oxygenation. Higher baseline oxygenation and cytochrome density in layer IV may serve as an $\mathrm{O}_{2}$ reserve during surges of neuronal activity or certain metabolically active brain states rather than baseline energy needs. Our study provides the first quantification of microscopically resolved $\mathrm{CMRO}_{2}$ across cortical layers as a step towards informed interpretation and modeling of cortical-layer-specific Blood Oxygen Level Dependent (BOLD) functional Magnetic Resonance Imaging (fMRI) signals.
\end{abstract}




\section{Introduction}

Dramatic improvements in functional Magnetic Resonance Imaging (fMRI) technology in recent years, including significant advances in hardware and image reconstruction (Polimeni \& Wald 2018, Ugurbil 2018, Wald 2012, Yu et al 2014), have enabled resolution of cortical layers bringing us one step closer to the spatial scale of local neuronal circuits (Dumoulin et al 2018, Goense et al 2016, Polimeni et al 2010, Turner 2016). Indeed, neuronal circuits in cerebral cortex are organized in layers that differ in their cellular density, composition and wiring (Helmstaedter et al 2007, Woolsey \& Van der Loos 1970), as well as the density of mitochondrial cytochrome oxidase, a marker of $\mathrm{O}_{2}$ metabolism (Wong-Riley 1989). In primary cortices, the highest density of cytochrome oxidase is found in layer IV, and the lowest - in layer I (Land \& Simons 1985, Weber et al 2008). Therefore, it is commonly believed that layer IV has higher cerebral metabolic rate of $\mathrm{O}_{2}\left(\mathrm{CMRO}_{2}\right)$ compared to other layers. These differences have been specifically hypothesized to reflect laminar variation in metabolic costs under the baseline (unstimulated) conditions (Weber et al 2008). Experimentally addressing this hypothesis is important for physiological interpretation of the Blood Oxygenation Level Dependent (BOLD) contrast used in cortical layer-resolved fMRI studies (Dumoulin et al 2018, Goense et al 2012, Hirano et al 2011, Siero et al 2015, Yu et al 2014).

Experimental measurement of layer-specific (i.e. laminar) $\mathrm{CMRO}_{2}$ has been challenging, because in common practice it requires information about both blood oxygenation and blood flow (Devor et al 2012a, Devor et al 2012b, Dunn et al 2005, Royl et al 2008). Previously, we introduced a method for extraction of $\mathrm{CMRO}_{2}$ (Sakadzic et al 2010) based on a single imaging modality: 2-photon phosphorescence lifetime microscopy (2PLM) (Finikova et al 2008, Lecoq et al 2011, Sakadzic et al 2010) providing measurements of the partial pressure of $\mathrm{O}_{2}\left(\mathrm{pO}_{2}\right)$. This method relies on the Krogh-Erlang model of $\mathrm{O}_{2}$ diffusion from a cylinder (Krogh 1919), which assumes that a volume of tissue within a certain radius around a blood vessel gets all its $\mathrm{O}_{2}$ from that blood vessel. Previously, we applied our method to estimate $\mathrm{CMRO}_{2}$ in the rat cerebral 
cortex, where capillaries were absent within an $\sim 100-\mu \mathrm{m}$ radius around penetrating arterioles satisfying the model assumption. The laminar profile of $\mathrm{CMRO}_{2}$, however, has not been addressed due to limited penetration of our imaging technology at that time.

In the present study, we increased our penetration depth by (i) utilizing a new $\mathrm{pO}_{2}$ probe Oxyphor 2P with red-shifted absorption and emission spectra (Esipova et al 2019), (ii) switching from rats to mice since mice have a thinner cortex and smaller diameter of surface blood vessels attenuating light, and (iii) optimizing our procedure of probe delivery to avoid spilling of the probe on the cortical surface exacerbating out-of-focus excitation. With these improvements, we performed $\mathrm{pO}_{2}$ measurements in fully awake mice in cortical layers I-IV.

In the mouse cortex, periarteriolar spaces void of capillaries are narrower than those in the rat (Kasischke et al 2011, Uhlirova et al 2016b). This challenges the basic Krogh-Erlang assumption of the center arteriole serving as the sole $\mathrm{O}_{2}$ source. Therefore, we revisited the model to account for the contribution of the capillary bed and then applied the revised model to quantify the baseline laminar $\mathrm{CMRO}_{2}$ profile. Our results show that, contrary to the common notion (Weber et al 2008), baseline $\mathrm{CMRO}_{2}$ in layer IV does not exceed that in the upper cortical layers. We speculate that higher cytochrome oxidase density in layer IV may reflect higher $\mathrm{O}_{2}$ metabolism during transient surges of neuronal activity or certain metabolically active brain states rather than baseline energy needs. 


\section{Results}

\section{Depth-resolved measurements of tissue $\mathrm{pO}_{2}$ in awake mice with chronic optical} windows

We used 2PLM (Fig. 1A) (Finikova et al 2008, Lecoq et al 2011, Sakadzic et al 2010) in combination with a new $\mathrm{pO}_{2}$ probe Oxyphor 2P (Esipova et al 2019) to image baseline interstitial (tissue) $\mathrm{pO}_{2}$ in the primary cerebral cortex (SI) around diving arterioles at different depths: from the cortical surface down to $\sim 500 \mu \mathrm{m}$ deep. All measurements were performed in awake mice with chronically implanted optical windows (Fig. 1B-C and Suppl Fig. 1). Oxyphor 2P was pressure-microinjected into the cortical tissue $\sim 400 \mu \mathrm{m}$ below the surface and was allowed to diffuse resulting in sufficient signal intensity in cortical layers I-IV within $\sim 40$ min after the injection. Sulforhodamine 101 (SR101) was co-injected with Oxyphor 2P to label astrocytes as a means for real-time monitoring of tissue integrity. In addition, fluorescein isothiocyanate (FITC)labeled dextran was injected intravenously to visualize the vasculature. We imaged $\mathrm{pO}_{2}$ using either square or radial grids of 400 points in the $X Y$ plane covering an area around a diving arteriole up to $\sim 200 \mu \mathrm{m}$ in the radial distance. Overall, $\mathrm{pO}_{2}$ measurements were acquired at 24 planes along 6 diving arterioles in 4 subjects.

We traced individual diving arterioles from the cortical surface and acquired grids of $\mathrm{pO}_{2}$ points with an arteriole at the center (Fig. 1D and Suppl Fig. 2). Figure 1E shows an example imaging plane crossing a diving arteriole. For each plane, a corresponding "reference" vascular image of intravascular FITC fluorescence was acquired immediately before and immediately after the $\mathrm{pO}_{2}$ measurements for coregistration of the measurement points in the coordinate system of the vascular network. The measurements are color-coded according to the $\mathrm{pO}_{2}$ level (in $\mathrm{mmHg}$ ) and superimposed on the reference vascular image (Fig. 1F).

We grouped $\mathrm{pO}_{2}$ measurements according to the following depth categories: layer I (50$100 \mu \mathrm{m})$, layer II/II $(150-300 \mu \mathrm{m})$ and layer IV $(320-500 \mu \mathrm{m})$. Figure 1G shows distributions of 
tissue $\mathrm{pO}_{2}$ values for the specific example shown in Figure 1E-F, and Figure $\mathbf{1 H}$ shows similar histograms for the overall dataset pooled across subjects. The high tail of the overall $\mathrm{pO}_{2}$ distribution (the upper 35\%), reflecting oxygenation in tissue in the immediate vicinity of arterioles, did not change significantly as a function of depth. This lack of dependence of the peri-arteriolar $\mathrm{pO}_{2}$ on depth is in agreement with recent depth-resolved intravascular $\mathrm{pO}_{2}$ studies in awake mice by us and others showing only a small decrease in the intravascular $\mathrm{pO}_{2}$ along diving arteriolar trunks (Li et al 2019, Lyons et al 2016, Sencan et al 2020). In contrast, there was a significant increase in the low tail (the bottom 35\%) of the $\mathrm{pO}_{2}$ distribution with depth (Fig. 1I, p<0.05) presumably indicating an increase in oxygenation of tissue in between capillaries in layer IV compared to layer I. This depth-dependent increase questions the common believe that layer IV has higher baseline $\mathrm{CMRO}_{2}$ compared to other layers. In addition, the median of the $\mathrm{pO}_{2}$ distribution shifted to the higher $\mathrm{pO}_{2}$ values below $200 \mu \mathrm{m}$ (Fig. $1 \mathrm{H}$ ). The median increase can be explained, at least in part, by branching: at certain depths, diving arterioles branched leading to the presence of highly oxygenated vessels (arterioles and capillaries) in the vicinity of diving arteriolar trunks.

\section{ODACITI model for $\mathrm{CMRO}_{2}$ extraction}

To quantify the laminar profile of $\mathrm{CMRO}_{2}$ in mouse cerebral cortex, we revised our model for estimation of $\mathrm{CMRO}_{2}$ based on peri-arteriolar $\mathrm{pO}_{2}$ measurements. The vascular architecture in the cerebral cortex features the absence of capillaries around diving arterioles (Kasischke et al 2011, Sakadzic et al 2014, Sakadzic et al 2016). Previously, we and others have argued that this organization agrees with the Krogh-Erlang model of $\mathrm{O}_{2}$ diffusion from a cylinder (Krogh 1919), where a diving arteriole can be modeled as a single $\mathrm{O}_{2}$ source for the tissue in the immediate vicinity of that arteriole where no capillaries are present. Indeed, radial $\mathrm{pO}_{2}$ gradients around cortical diving arterioles in the rat SI approached zero at the tissue radii corresponding 
to the first appearance of capillaries, and application of this model to estimate $\mathrm{CMRO}_{2}$ yielded physiologically plausible results (Sakadzic et al 2016). In the mouse, however, capillary-free peri-arteriolar spaces are smaller compared to those in the rat, and $\mathrm{O}_{2}$ delivery by the capillary bed cannot be ignored (Moeini et al 2019). Therefore, we revised the model to explicitly include both arteriolar and capillary delivery as we describe below.

In the Krogh-Erlang model, a blood vessel - approximated as an infinitely long cylinder has a feeding tissue territory with a radius $r=R_{t}$. Outside of this cylinder, we enter a feeding territory of other vessels. Therefore, according to the Krogh-Erlang model, tissue $\mathrm{pO}_{2}$ will monotonically decrease with $r$ while moving away from the vessel until we reach $R_{t}$. The minimum occurs at $r=R_{t}$, where the first spatial derivative along the radial direction is zero $\left(d \mathrm{PO}_{2} / d r=0\right)$. Outside of this cylinder, the predicted $\mathrm{pO}_{2}$ for $r>R_{t}$ has no physiological meaning as the model is defined for $r \leq R_{t}$. However, Krogh-Erlang formula for $r>R_{t}$ predicts rapid $\mathrm{pO}_{2}$ increase, which is not compatible with the experimental observations of small tissue $\mathrm{pO}_{2}$ changes in the capillary bed and it complicates the fitting procedure (Sakadzic et al 2016). Importantly, in the cerebral cortex, not only arterioles but also capillaries contribute to tissue oxygenation, and this contribution is larger in awake animals ( Li et al 2019, Sencan et al 2020) compared to those under anesthesia (Sakadzic et al 2014). However, radial $\mathrm{pO}_{2}$ changes around capillaries are still small (Li et al 2019, Lu et al 2020) and our current $\mathrm{pO}_{2}$ measurements are not optimal for accurately mapping them. Therefore, to account for the $\mathrm{pO}_{2}$ distribution in the capillary bed $\left(r>R_{t}\right)$, we revised the model assumptions as follows: (i) similar to the KroghErlang model, we assumed that within a certain circular distance around a diving arteriole $\left(r<R_{t}\right)$, the arteriole in the center is the dominant source of $\mathrm{O}_{2}$ such that $\frac{1}{r} \frac{\partial}{\partial r}\left(r \frac{\partial p O_{2}(r)}{\partial r}\right)=\mathrm{CMRO}_{2} /(\alpha D)$ , where $\alpha$ and $D$ are $\mathrm{O}_{2}$ solubility and diffusivity, respectively; (ii) for $\left(r>R_{t}\right)$, we assume that the $\mathrm{O}_{2}$ supply from capillaries is uniformly distributed and equal 
to the $\mathrm{O}_{2}$ consumption, such that

$\frac{1}{r} \frac{\partial}{\partial r}\left(r \frac{\partial p O_{2}(r)}{\partial r}\right)=0$

The new model, which we call ODACITI $\left(\mathbf{O}_{2}\right.$ Diffusion from Arterioles and

Capillaries Into TIssue), is schematically illustrated in Figure 2A. As for the Krogh-Erlang model, the central arteriole (red) with the radius $r=R_{\text {ves }}$ is feeding the peri-arterial tissue (Fig. 2A, pink) with the radius $r=R_{t}$. Beyond that, $\mathrm{O}_{2}$ is supplied by the capillary bed so that the second spatial derivative is zero for $r>R_{t}$ (Fig. 2A, blue). With this set of assumptions, we derived a new specific solution to the forward Poisson problem in cylindrical coordinates (see Methods).

\section{Validation of the ODACITI model using synthetic data}

To validate the ODACITI model, we used synthetic data where the ground truth (spaceinvariant) $\mathrm{CMRO}_{2}$ was preset and thus known. First, we compared the functional form of the radial $\mathrm{pO}_{2}$ gradient obtained with ODACITI to that obtained with the Krogh-Erlang equation. To that end, we generated synthetic data by analytically solving the Krogh-Erlang and ODACITI equation for a given $\mathrm{CMRO}_{2}$ and $R_{t}$. As expected, the models agree for $r<R_{t}$ producing the same monotonic decrease in $\mathrm{pO}_{2}$ with increasing distance from the center arteriole. Beyond $R_{t}$, the Krogh-Erlang formula produces an unrealistic increase in $\mathrm{pO}_{2}$, while ODACITI is able to take into account measured tissue $\mathrm{pO}_{2}$ in the capillary bed and it produces more realistic, nearly constant level of $\mathrm{pO}_{2}$ (Fig. 2B). Next, we tested ODACITI on synthetic data with added noise to mimic noise of experimental measurements. To that end, we (1) amended the Krogh-Erlang solution by imposing a constant $\mathrm{pO}_{2}$ equal to $\mathrm{pO}_{2}\left(\mathrm{R}_{\mathrm{t}}\right)$ for $r>R_{t}$ to represent the capillary bed, and (2) added Gaussian noise $(\sigma=2)$. With these synthetic data, we were able to sufficiently recover the true $\mathrm{CMRO}_{2}$ with ODACITI (Fig. 2C). In another test, we performed fitting while selecting a constant $R_{t}$ between $60-80 \mu \mathrm{m}$. This resulted in an $18 \%$ error in the estimated 
$\mathrm{CMRO}_{2}$ (Suppl. Fig. 3). In comparison, the same variation in $R_{t}$ resulted in a $45 \%$ error while using a fitting procedure developed in Sakadzic et al. 2014 to fit for $\mathrm{CMRO}_{2}$ based on the KroghErlang model (Sakadzic et al 2014). Thus, ODACITI is less sensitive to the error in $R_{t}$ compared to the Krogh-Erlang model.

ODACITI assumes that the first spatial derivative $d p \mathrm{O}_{2}(r) / d r$ monotonically decreases in the proximity of the arteriole and remains near zero in the capillary bed. In reality, however, this derivative varies in different directions from the center arteriole due to asymmetry of the vascular organization. Moreover, for some radial directions, $\mathrm{pO}_{2}$ may remain high due to the presence of another highly oxygenated vessel (a small arteriolar branch or highly oxygenated capillary ( $\mathrm{Li}$ et al 2019, Sakadzic et al 2014). To model this situation, we placed additional $\mathrm{O}_{2}$ sources representing highly oxygenated blood vessels around the center arteriole (Fig. 2D). When multiple nearby vessels serve as $\mathrm{O}_{2}$ sources, no analytical solution for the tissue $\mathrm{pO}_{2}$ map is available. Therefore, we solved the Poisson equation, which relates $\mathrm{CMRO}_{2}$ and tissue $\mathrm{pO}_{2}$, by means of finite-element numerical modeling implemented in the software package FEniCS (Logg et al 2012) (see Methods). Previously, we verified this implementation (for simple vascular geometries) by comparing the result to that of the Krogh-Erlang equation (Saetra et al 2020). Fig. 2D illustrates an example FEniCS output for a center 15- $\mu$ m-diameter "arteriole" surrounded by seven 5 - $\mu$ m-diameter "capillaries" located $80-130 \mu \mathrm{m}$ away from the diving arteriole (Fig. 2D), which is a typical size of the region around diving arterioles void of capillaries in mouse cerebral cortex. The intravascular $\mathrm{pO}_{2}$ was set to $70 \mathrm{mmHg}$ and $35 \mathrm{mmHg}$ for the arteriole and capillaries, respectively. In addition, we placed another "arteriole" with intravascular $\mathrm{pO}_{2}$ was set to $60 \mathrm{mmHg} 110 \mu \mathrm{m}$ away from the center arteriole to simulate the occasional presence of highly oxygenated vessels within our measurement grid.

These simulated data were used to devise a procedure for segmenting a region of interest $(\mathrm{ROI})$ consistent with the assumption that $\mathrm{pO}_{2}$ should decrease monotonically from the 
center arteriole until reaching a certain steady-state value within the capillary bed (see Methods). We then used the data included in the $\mathrm{ROI}$ to extract the $\mathrm{pO}_{2}$ profile as a function of the radial distance from the center arteriole. Finally, we applied the ODACITI model to these radial $\mathrm{pO}_{2}$ profiles to calculate $\mathrm{CMRO}_{2}$. We calculated $\mathrm{CMRO}_{2}$ in a noise-free case as well as with additive Gaussian noise (see Methods). In both cases, the model was able to recover the true $\mathrm{CMRO}_{2}$ (Fig. 2E-F).

\section{Estimation of $\mathrm{CMRO}_{2}$ across cortical layers}

Following validation with synthetic data (Fig. 2), we used ODACITI to calculate $\mathrm{CMRO}_{2}$ across the cortical depth keeping the same depth categories as in Figure 1. For each imaging plane, we registered a $\mathrm{pO}_{2}$ measurement grid with the corresponding vascular reference image. As with synthetic data, we segmented an ROI for each measurement grid and collapsed the data within each $\mathrm{ROI}$ into a corresponding radial $\mathrm{pO}_{2}$ gradient (Fig. 3A, see Methods). These peri-arteriolar $\mathrm{pO}_{2}$ gradients are consistent with our previous measurements in the rat cortex under $\alpha$-chloralose anesthesia (Devor et al 2011) and a more recent study in superficial cortex of awake mice (Lu et al 2020). Next, we performed fitting of the data to the ODACITI solution to quantify $\mathrm{CMRO}_{2}$ (Fig. 3B) (see Methods). Figure 3C shows laminar (depth-resolved) $\mathrm{CMRO}_{2}$ profiles along 6 diving arterioles in 4 subjects. We used a mixed effects model implemented in $R$ to quantify $\mathrm{CMRO}_{2}$ across the layers. This analysis revealed a significant reduction of $\mathrm{CMRO}_{2}$ with depth ( $p=0.001$, Fig. 3D). For this calculation, $R_{t}$ was fixed at $80 \mu \mathrm{m}$ (see Methods); allowing $R_{t}$ to vary while fitting for $\mathrm{CMRO}_{2}$ did not reveal dependence of $R_{t}$ on cortical depth (not shown).

For each arteriole, we also acquired $\mathrm{pO}_{2}$ measurements at the cortical surface (Suppl Fig. 4). The surface measurements, however, were not used for estimation of $\mathrm{CMRO}_{2}$ because of violation of the axial symmetry assumption (i.e., absence of cerebral tissue above the imaging 
plane).

Graphically, $\mathrm{CMRO}_{2}$ scales with the steepness of the descent of peri-arteriolar radial $\mathrm{pO}_{2}$ profile (Kasischke et al 2011, Krogh 1919, Saetra et al 2020, Sakadzic et al 2016). In Figure 3E, we overlay grand averaged radial profiles for each layer. Each curve was obtained by averaging all data for that layer (Suppl Fig.5). As can be appreciated by visual inspection, the gradient corresponding to layer I has the steepest descent, while the descent of gradient in layer IV is more relaxed. This indicates that $\mathrm{CMRO}_{2}$ in layer IV is lower compared to the upper layers, which is consistent with the model-based estimation shown in Figure 3D.

Taken together, our results indicate that an increase in the low tail of the $\mathrm{pO}_{2}$ distribution with depth, which likely reflects an increase in oxygenation of tissue in between capillaries in layer IV compared to upper layers (Fig. 1H-I), can be explained at least in part by a depthdependent decrease in $\mathrm{CMRO}_{2}$ from layer I to layer IV (Fig. 3D-F). This is in contrast to a wellestablished fact that capillary, cytochrome oxidase, and mitochondrial densities in the mouse SI all peak in layer IV (Blinder et al 2013, Santuy et al 2018) implying that neither of these densities can serve as a proxy for oxidative energy metabolism under baseline (unstimulated) conditions. 


\section{Discussion}

In this work, we have achieved depth-resolved tissue $\mathrm{pO}_{2}$ measurements in fully awake mice using 2PLM in combination with the $\mathrm{O}_{2}$-sensitive probe Oxyphor-2P. We devised the ODACITI model for estimation of $\mathrm{CMRO}_{2}$ from peri-arteriolar $\mathrm{pO}_{2}$ gradients accounting for both arteriolar and capillary $\mathrm{O}_{2}$ supply. We validated the model using synthetic data and then applied it to estimate the laminar $\mathrm{CMRO}_{2}$ profile during the baseline level of neuronal activity (i.e., in the absence of external stimulation). Our results demonstrate a significant reduction of $\mathrm{CMRO}_{2}$ with depth from layer I to layer IV. While these results are based on a model and its specific assumptions, they strongly suggest that, at the very least, the baseline $\mathrm{CMRO}_{2}$ in layer IV does not exceed that in the upper cortical layers.

In cerebral cortex, neuronal cell type distribution as well as cellular, synaptic and microvascular densities vary between cortical layers (Blinder et al 2013, Feldmeyer et al 2013, Harris \& Shepherd 2015, Helmstaedter et al 2007, Hyder et al 2013, Li et al 2019, Markram et al 2004, Weber et al 2008, Wu et al 2016). Cortical laminar architecture is also readily revealed by counting mitochondria (Santuy et al 2018) or staining for cytochrome oxidase - the last enzyme in the respiratory electron transport chain located in the mitochondrial membrane (Weber et al 2008, Wong-Riley 1989). In SI, cytochrome oxidase distribution features a high-density band in cortical layer IV, which has been hypothesized to reflect higher $\mathrm{CMRO}_{2}$ compared to other layers. Further, cytochrome oxidase was found to have a strong correlation with microvascular but not synaptic density - a finding that was interpreted to reflect high layer IV $\mathrm{CMRO}_{2}$ in the "idling state" (Weber et al 2008), where about half of the energy expenditure reflects other processes than synaptic and spiking activity (Attwell \& Laughlin 2001, Engl \& Attwell 2015). The present measurements and calculations do not support the idea of high baseline $\mathrm{CMRO}_{2}$ in layer IV. 
If so, what is the purpose of high cytochrome oxidase density in layer IV? In our recent study, we found that intravascular $\mathrm{pO}_{2}$ changes $\left(\Delta \mathrm{pO}_{2}\right)$ in response to a sensory stimulus across layers were conserved (Sencan et al 2020) indicating a conserved ratio between the demand and supply. Taken together with existing data on larger stimulus-induced increases in CBF $(\triangle \mathrm{CBF})$ in layer IV compared to other layers (Srinivasan \& Radhakrishnan 2014), this finding implies that the laminar $\Delta \mathrm{CMRO}_{2}$ profile should also peak in layer IV in order for $\Delta \mathrm{pO}_{2}$ to remain invariant. Thus, cytochrome oxidase may reflect layer-specific differences in peak energetic demands during transient neuronal signaling events. These events may include not only taskinduced computation performed by local neuronal circuits (e.g., Barrel cortex response to a whisker touch (Feldmeyer et al 2013)) but also other dynamic neuronal processes occurring on larger spatiotemporal scales such as neuromodulation and sleep (Madsen et al 1991).

In this study, we observed a shift towards higher oxygenation of tissue within the capillary bed - quantified as the mean of the low tail of $\mathrm{pO}_{2}$ distribution - with increasing depth. Because our $\mathrm{pO}_{2}$ grids were always placed around diving arterioles, the low tail of the $\mathrm{pO}_{2}$ distribution may not reflect oxygenation of the capillary bed remote from arteriolar $\mathrm{O}_{2}$ sources. This observation, however, is potentially in line with our recent intravascular $\mathrm{pO}_{2}$ study in awake mice, where we showed that mean capillary $\mathrm{pO}_{2}$ in layer IV was $\sim 15 \%$ higher than that in the upper layers ( $\mathrm{Li}$ et al 2019). It is also consistent with a recent study where tissue $\mathrm{pO}_{2}$ measurements were performed at different depths while a Clark-type polarographic electrode was advanced throughout cortical layers (Zhang et al 2019). We speculate that higher baseline oxygenation in layer IV may serve as an $\mathrm{O}_{2}$ reserve for transient increases in neuronal activity. Beyond this reserve, upregulation in aerobic glycolysis may play a role alongside oxidative phosphorylation to rapidly supply ATP (Dienel 2019, Raichle \& Mintun 2006, Yellen 2018).

In principle, higher capillary density in layer IV (Blinder et al 2013) may effectively shrink the peri-arteriolar cylinder where all $\mathrm{O}_{2}$ is provided by the diving arteriole. This hypothetical 
scenario, however, would not affect the $\mathrm{pO}_{2}$ gradient around the arteriole (which reflects $\mathrm{CMRO}_{2}$ ). Rather, it would decrease the radius of this cylinder, $R_{t}$. Although in our calculations of $\mathrm{CMRO}_{2} R_{t}$ was a fixed parameter, we show that sensitivity of ODACITI to varying $R_{t}$ was relatively low. In addition, allowing $R_{t}$ to vary while fitting for $\mathrm{CMRO}_{2}$ did not reveal depthdependence.

The current study is part of our ongoing effort to improve 2PLM (Devor et al 2011, Devor et al 2013, Esipova et al 2019, Li et al 2019, Sakadzic et al 2010, Sakadzic et al 2016, Sencan et al 2020) and microscopic estimation of $\mathrm{CMRO}_{2}$ (Saetra et al 2020, Sakadzic et al 2016, Uhlirova et al 2016a). In principle, if we knew space-resolved tissue $\mathrm{pO}_{2}$ as well as intravascular $\mathrm{pO}_{2}$ for each blood vessel within that tissue, we could solve for $\mathrm{CMRO}_{2}$ (that may vary in space and time) by finding an inverse solution for the Poisson diffusion equation (Saetra et al 2020). In practice, however, the signal to noise ratio (SNR) of our measurements may not be sufficient to accurately resolve $\mathrm{pO}_{2}$ gradients around capillaries. In addition, our current spatial resolution limits simultaneous measurements of capillary and tissue $\mathrm{pO}_{2}$, and sampling $\mathrm{pO}_{2}$ in $3 \mathrm{D}$ also remains a challenge. To mitigate these limitations, similar to the Krogh-Erlang model, the ODACITI model relies on radial $\mathrm{pO}_{2}$ gradients around diving arterioles assuming cylindrical symmetry. In reality, highly oxygenated arteriolar branches and/or low branching order capillaries can often be present on one side of a diving arteriole requiring ROI segmentation. Applied to synthetic data, our data analysis stream - including the segmentation algorithm followed by ODACITI estimation - was able to recover the "ground truth" $\mathrm{CMRO}_{2}$ validating the method. In the future, further improvements in $\mathrm{pO}_{2}$ probes and 2PLM technology may enable estimation of $\mathrm{CMRO}_{2}$ in $3 \mathrm{D}$ using numeric methods without the need to segment the data (Saetra et al 2020).

Our measurements were limited to cortical layers I-IV. In 2-photon microscopy, depth penetration is fundamentally limited by out-of-focus excitation (Theer \& Denk 2006). Because 
light is scattered and absorbed by tissue, the laser power is ought to increase with depth to overcome these effects and deliver a sufficient number of photons to the focal volume. In our experiment, an increase in the number of scattered photons would increase the probability of out-of-focus excitation of Oxyphor 2P generating background phosphorescence. The lifetime of this background phosphorescence would report $\mathrm{pO}_{2}$ at locations outside the focal volume contributing to the experimental error and smoothing out peri-arteriolar $\mathrm{pO}_{2}$ gradients. In the future, a combination of 2PLM with light sculpting techniques (Rupprecht et al 2015) can be used to experimentally measure the amount of generated out-of-focus signal. 2PLM can also be implemented using two laser beams of different color that can be displaced in space minimizing out-of-focus excitation (Cheng et al 2020, Sadegh et al 2019).

This study was performed using fully awake mice with no anesthesia or sedation. While our mice were well trained to accept the head restraint and habituated to the imaging environment, we cannot rule out upregulation of adrenergic activity associated with arousal and/or stress. Previous studies have shown that aerobic glycolysis and glycogenolysis are triggered by activation of $\beta 1$ and $\beta 2$ adrenergic receptors, respectively (Dienel 2019, Dienel \& Cruz 2016, Zuend et al 2020). Both of these processes are layer-specific in cerebral cortex. Therefore, the relative contribution of oxidative and glycolytic pathways to overall energy metabolism across cortical layers can depend on the state of adrenergic neuromodulation (Machler et al 2021). In the future, a combination of 2PLM with imaging of novel genetically encoded probes for norepinephrine and other neuromodulators (Feng et al 2019, Sabatini \& Tian 2020) should allow quantification of $\mathrm{CMRO}_{2}$ in context of different brain states.

Knowing layer-specific $\mathrm{CMRO}_{2}$ in cerebral cortex is important for better understanding of the normal brain physiology as well as pathophysiology in diseases that affect cerebral microcirculation (Berthiaume et al., 2018; Iadecola, 2016, 2017; Pantoni, 2010; Zlokovic, 2011). It also is important for interpretation and modeling of the BOLD fMRI signals that are affected by both CBF and $\mathrm{CMRO}_{2}$ (Buxton 2010, Gagnon et al 2015, Uhlirova et al 2016a). Of particular 
relevance to the current results, the BOLD response is sensitive not only to the balance of the $\triangle \mathrm{CBF}$ and $\triangle \mathrm{CMRO}_{2}$ but also to their baseline state that can vary with age, disease, or even after consuming a cup of coffee (Griffeth et al 2011, Perthen et al 2008) altering the hemodynamic response for the same neuronal reality. Our study provides the first quantification of baseline $\mathrm{CMRO}_{2}$ across cortical layers as a step towards informed interpretation and modeling of high resolution BOLD signals.

\section{Methods}

\section{$\mathrm{O}_{2}$ probe}

The synthesis and calibration of the $\mathrm{O}_{2}$ probe Oxyphor 2P were performed as previously described (Esipova et al 2019). The phosphorescence lifetime of Oxyphor 2P is inversely proportional to the $\mathrm{O}_{2}$ concentration. Compared to its predecessor PtP-C343 (Finikova et al 2008), the optical spectrum of Oxyphor $2 \mathrm{P}$ is shifted to the longer wavelengths with the 2photon absorption and phosphorescence peaks at $960 \mathrm{~nm}$ and $760 \mathrm{~nm}$, respectively, enabling deeper imaging. Other advantages include large 2-photon absorption cross section ( 600 GM near $960 \mathrm{~nm}$ ) and higher phosphorescence quantum yield (0.23 in the absence of $\left.\mathrm{O}_{2}\right)$. In addition, the phosphorescence decay of Oxyphor 2P can be more closely approximated by a single-exponential function. Calibration for conversion of the phosphorescence lifetime to $\mathrm{pO}_{2}$ was obtained in independent experiments, where $\mathrm{pO}_{2}$ was detected by a Clark-type electrode as previously described (Esipova et al 2019).

\section{Two-photon imaging}

Images were obtained using an Ultima 2-photon laser scanning microscopy system (Fig. 1A) (Bruker Fluorescence Microscopy). Two-photon excitation was provided by a Chameleon Ultra femtosecond Ti:Sapphire laser (Coherent) tuned to $950 \mathrm{~nm}$. 
For 2-photon phosphorescence lifetime microscopy (2PLM), laser power and excitation gate duration were controlled by two electro-optic modulators (EOMs) (350-160BK, Conoptics) in series with an effective combined extinction ratio $>50,000$. This was done to mitigate bleedthrough of the laser light and reduce the baseline photon count (i.e., during gate-OFF periods), which was critical for accurately fitting phosphorescence decays.

We used a combination of Zeiss $5 x$ objective (Plan-NEOFLUAR, NA=0.16) for a coarse imaging and Olympus 20x (UMPlanFI, NA=0.5) objective for fine navigation under the glass window and for 2PLM. An objective heater (TC-HLS-05, Bioscience Tools) was used to maintain the temperature of the water between the objective lens and cranial window at $36.6{ }^{\circ} \mathrm{C}$ to avoid the objective acting as a heat sink and to comply with the Oxyphor $2 \mathrm{P}$ calibration temperature (Li et al 2019, Podgorski \& Ranganathan 2016, Roche et al 2019).

The emission of Oxyphor $2 \mathrm{P}$ was reflected with a low-pass dichroic mirror (900-nm cutoff wavelength; custom-made by Chroma Technologies), subsequently filtered with a 795/150$\mathrm{nm}$ emission filter (Semrock) and detected using a photon counting photomultiplier tube (PMT, Hamamatsu, H7422P-50). A second PMT, operated in analog mode (H7422-40, Hamamatsu) with $525 / 50 \mathrm{~nm}$ or $617 / 73 \mathrm{~nm}$ emission filters (Semrock) was used to detect fluorescein isothiocyanate (FITC)-labeled dextran and astrocytic marker sulforhodamine 101 (SR101), respectively (see Delivery of optical probes below). A 950-nm short-pass filter (Semrock) was positioned in front of the PMTs to further reject laser illumination.

At each imaging plane up to $400 \mu \mathrm{m}$ below the cortical surface, a $\sim 300 \times 300 \mu \mathrm{m}$ field of view (FOV) was selected for $\mathrm{pO}_{2}$ measurements. At each plane, $\mathrm{pO}_{2}$ measurements were performed serially arranged in a square or radial grid of 400 points.

The phosphorescence was excited using a $13-\mu \mathrm{s}-$ long excitation gate, and the emission decay was acquired during $287 \mu$ s. The photon counts were binned into 2 - $\mu$ s-long bins. Typically, 50 decays were accumulated at each point with the total acquisition time of $15 \mathrm{~ms}$ per 
point. With 400 points per grid, one grid was acquired within 6 s. All points were revisited 20 times yielding a total of 1000 excitation cycles per point (50 cycles $\times 20$ repetitions) acquired within 120 s. Dividing acquisition of 1000 cycles per point in blocks of 20 repetitions increased tolerance against motion (see Motion correction below) at a price of a slightly reduced sampling rate due to settling time of the galvonometer mirrors while moving from point to point.

\section{Implantation of the cranial window and headpost}

All animal procedures were performed in accordance with the guidelines established by the Institutional Animal Care and Use Committee (IACUC) at University of California, San Diego. We used 13 adult C57BL/6J mice of either sex (age: 4-7 months). Seven of them were rejected due to imperfect healing of the cranial window, and 6 were used for $\mathrm{pO}_{2}$

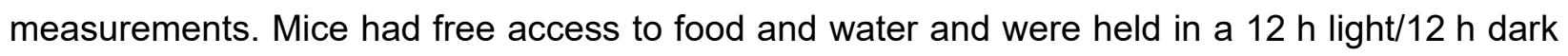
cycle.

The surgical procedure for implantation of a chronic optical window was performed as previously described (Desjardins et al 2019, Kilic et al 2020). Briefly, dexamethasone was injected $\sim 2 \mathrm{~h}$ prior to surgery. Mice were anesthetized with ketamine/xylazine or isoflurane ( $2 \%$ in $\mathrm{O}_{2}$ initially, $1 \%$ in $\mathrm{O}_{2}$ for maintenance) during surgical procedures; their body temperature was maintained at $37^{\circ} \mathrm{C}$. A 3-mm cranial window with a silicone port was implanted over the left barrel cortex, and the headpost was mounted over the other (right) hemisphere. The glass implant contained a hole, filled with silicone (Kilic et al 2020, Roome \& Kuhn 2014), allowing intracortical injection of the $\mathrm{O}_{2}$ probe (Fig.1B and Suppl. Fig. 1). The window and the headpost were fixed to the skull in a predetermined orientation such that, when the mouse head was immobilized in the mouse holder ("hammock"), the window plane would be horizontal. Dextrose saline $(5 \%$ dextrose, $0.05 \mathrm{ml})$ was injected subcutaneously before discontinuing anesthesia. Post-operative analgesia was provided with buprenorphine $(0.05 \mathrm{mg} / \mathrm{kg}$ subcutaneously) injected $\sim 20 \mathrm{~min}$ before discontinuing anesthesia. A combination of 
sulfamethoxazole/trimethoprim (Sulfatrim) $\quad(0.53 \mathrm{mg} / \mathrm{mL}$ sulfamethoxazole and $0.11 \mathrm{mg} / \mathrm{mL}$ trimethoprim), and ibuprofen $(0.05 \mathrm{mg} / \mathrm{ml})$ was provided in drinking water starting on the day of surgery and for 5 days after surgery. Generally, full recovery and return to normal behavior were observed within $48 \mathrm{~h}$ post-op.

\section{Delivery of optical probes}

Oxyphor 2P and astrocytic marker SR101 were delivered by intracortical microinjection through the silicon port in the glass window (Fig. 1B and Suppl. Fig. 1). Oxyphor 2P was diluted to $340 \mu \mathrm{M}$ in artificial cerebrospinal fluid (ACSF, containing: $142 \mathrm{mM} \mathrm{NaCl}, 5 \mathrm{mM} \mathrm{KCl}$, $10 \mathrm{mM}$ glucose, $10 \mathrm{mM}$ HEPES (Na Salt), $3.1 \mathrm{mM} \mathrm{CaCl}_{2}, 1.3 \mathrm{mM} \mathrm{MgCl}_{2}, \mathrm{pH}$ 7.4) and filtered through a 0.2- $\mu \mathrm{m}$ filter (Acrodisc 4602, PALL). SR101 (Sigma S359) was added for a final concentration of $0.2 \mathrm{mM}$. We used quartz-glass capillaries with filament (O.D. $1.0 \mathrm{~mm}$, I.D. 0.6 mm; QF100-60-10; Sutter Instrument). Pipettes were pulled using a P-2000 Sutter Instrument Puller. For each pulled pipette, the tip was manually broken under the microscope to obtain an outer diameter of 15-25 $\mu \mathrm{m}$. A pipette was filled with a mixture of Oxyphor 2P and SR-101 (thereafter referred to as the "dye") and fixed in a micromanipulator at an angle of $\sim 35^{\circ}$. The pipette was guided under visual control through the silicon port to its final location in tissue while viewing the SR101 fluorescence through the microscope eyepiece. First, to target the tissue surrounding a diving arteriole, the pipette was oriented above the window such that its projection onto the window coincided with the line connecting the diving point with the silicon port. The pipette was then retracted and lowered to touch the surface of the port. There, a drop of the dye solution was ejected to ensure that the pipette was not clogged. A holding positive pressure was maintained (using PV830 Picopump, World Precision Instruments) to avoid clogging of the pipette while advancing through the port. An experimenter could recognize the pipette emerging below the port by the dye streaming from the tip. At this point, the holding 
pressure was quickly set to zero in order to avoid spilling of the dye on the cortical surface. Next, the pipette was advanced for $\sim 600 \mu \mathrm{m}$ along its axis at $35^{\circ}$. Below $\sim 100 \mu \mathrm{m}$, some holding pressure was applied to allow leakage of the dye that was used to visualize the pipette advancement. The pressure was manually adjusted to ensure visible spread of the dye without displacing cortical tissue. When the target artery was reached, the pipette was withdrawn by $\sim 50 \mu \mathrm{m}$, and holding pressure was maintained for $\sim 20 \mathrm{~min}$ to allow slow diffusion of the dye into the tissue. A successful injection was recognized by the appearance of SR101 in the perivascular space around the targeted arteriole but not around its neighbors. The contrast between the targeted and neighboring arterioles was lacking when the dye was injected too shallow or too vigorously, in which case the experiment was aborted. After the loading, the pressure was set to zero and the pipette was withdrawn. The mouse was placed back in its home cage to recover for $\sim 40$ minutes until the start of the imaging session. At that time, the dye usually diffused within a $300-600-\mu \mathrm{m}$ radius around the targeted arteriole.

FITC-dextran (FD2000S, $2 \mathrm{MDa}$, Sigma Aldrich) was used to visualize cortical vasculature. Mice were briefly anesthetized with isoflurane, and $50 \mu$ of the FITC solution (5\% in normal saline) was injected retro-orbitally prior to intracortical delivery of Oxyphor 2P for each imaging session.

\section{Habituation to head fixation}

Starting at least 7 days after the surgical procedure, mice were habituated in one session per day to accept increasingly longer periods of head restraint under the microscope objective (up to $1 \mathrm{~h} / \mathrm{day}$ ). During the head restraint, the mouse was placed on a hammock. $\mathrm{A}$ drop of diluted sweetened condensed milk was offered every 20-30 min during the restraint as a reward. Mice were free to readjust their body position and from time to time displayed natural grooming behavior. 


\section{Estimation of $\mathrm{pO}_{2}$}

All image processing was performed using custom-designed software in MATLAB (MathWorks). For each point, cumulative data from all excitation cycles available for that point were used for estimation of the phosphorescent decay. Starting $5 \mu$ s after the excitation gate to minimize the influence of the instrument response function, the decay was fitted to a singleexponential function:

$$
N(t)=N_{0} e^{-t / \tau}+x
$$

where $N(t)$ is the number of photons at time $t, N_{0}$ is the number of photons at $t=0$ (i.e., $5 \mu \mathrm{s}$ after closing the excitation gate), $\tau$ is the phosphorescence lifetime and $x$ is the offset due to non-zero photon count at baseline. The fitting routine was based on the nonlinear least-squares method using the MATLAB function Isqnonlin. The phosphorescence lifetime $\tau$ was then converted into absolute $\mathrm{pO}_{2}$ using an empirical biexponential form:

$$
p O_{2}=A_{1} e^{-\tau / t 1}+A_{2} e^{-\tau / t 2}+y_{0}
$$

Where parameters $A_{1}, t_{1}, A_{2}, t_{2}$ and $y_{0}$ were obtained during independent calibrations (Esipova et al 2019).

The locations of $\mathrm{pO}_{2}$ measurements were co-registered with FITC-labeled vasculature. Color-coded $\mathrm{pO}_{2}$ values are overlaid on vascular images (grayscale) in all figures displaying $\mathrm{pO}_{2}$ maps.

\section{Identification of data corrupted by motion}

To exclude data with excessive motion, an accelerometer (ADXL335, Sainsmart, Analog Devices) was attached below the mouse hammock. The accelerometer readout was synchronized with 2-photon imaging and recorded using a dedicated data acquisition system (National Instruments). During periods with extensive body movement (e.g., grooming 
behavior), the accelerometer signal crossed a pre-defined threshold, above which data were rejected. In pilot experiments, in addition to the accelerometer, a webcam (Lifecam Studio, Microsoft; IR filter removed) with IR illumination (M940L3-IR (940 nm) LED, Thorlabs) was used for video recording of the mouse during imaging. The video and accelerometer reading were in general agreement with each other. Therefore, accelerometer data alone were used to calculate the rejection threshold. Because every point was revisited 20 times, typically at least 10 repetitions (or 500 excitation cycles) were unaffected by motion and were used to estimate $\tau$. The MATLAB function Isqnonlin used to fit phosphorescent decays returned the residual error for each fit, that we plotted against the number of cycles (Suppl. Fig. 6). At around 500 cycles, the error stabilized at a low level. Therefore, we quantified points where at least 500 cycles were available.

\section{Estimation of $\mathrm{CMRO}_{2}$}

The $\mathrm{O}_{2}$ transport to tissue is thought to be dominated by diffusion. In the general case, the relationship between $\mathrm{pO}_{2}$ denoted as $P(\vec{r}, t)$ and the $\mathrm{O}_{2}$ consumption rate denoted $\mathrm{CMRO}_{2}(r, t)$ can be described by

$$
\partial P(\vec{r}, t) / \partial t=D \nabla^{2} P(\vec{r}, t)-C M R O_{2}(\vec{r}, t) / \alpha_{,}
$$

where $\boldsymbol{\nabla}^{2}$ is the Laplace operator in three spatial dimensions, and $D$ and $\alpha$ are diffusion coefficient and solubility of $\mathrm{O}_{2}$ in tissue, respectively. For all our calculations, we assumed $\alpha=$ $1.39 \mu \mathrm{M} \mathrm{mmHg}^{-1}$ and $\mathrm{D}=4 \times 10^{-5} \mathrm{~cm}^{2} \mathrm{~s}^{-1}$ (Goldman 2008). This equation is only applicable outside the blood vessels supplying $\mathrm{O}_{2}$ to the tissue. Oxygen supplied by a blood vessel is represented by a boundary condition of $\mathrm{pO}_{2}$ imposed at the vessel wall. When the system is in steady state, the term $\partial P(r, t) / \partial t$ can be neglected. If we also assume that there is no local variation of $\mathrm{pO}_{2}$ in the vertical $\mathrm{z}$-direction, that is, the direction along the cortical axis parallel to penetrating arterioles, Eq. 3 simplifies to 


$$
\nabla^{2} P(r)=\frac{C M R O_{2}\left(r_{s} t\right)}{D \pi}
$$

where $P(r)$ represents $\mathrm{pO}_{2}$ measured at the radial location $r$ and $\nabla^{2}$ refers to the twodimensional Laplace operator.

Here, we derive a specific solution to the forward problem of this partial differential equation using the following assumptions: First, as with the Krogh-Erlang model (Krogh 1919), we assume that tissue $\mathrm{CMRO}_{2}$ in the vicinity of a diving arteriole is space-invariant. Second, we assume that within a capillary-free region around the arteriole, all $\mathrm{O}_{2}$ is provided by that arteriole. That means that if we have an arteriole with the radius $\mathrm{r}=\mathrm{R}_{\mathrm{ves}}$ and a region around the arteriole void of capillaries within a radius $r=R_{t}$, for the radial distance $R_{\text {ves }}<r<R_{t}$, the rate of $\mathrm{O}_{2}$ consumption is equal to $\mathrm{CMRO}_{2}$ (that we are trying to find). This is because no local $\mathrm{O}_{2}$ sources are present within this region except for the arteriole in the center. Third, we assume that for $r>R_{t}$ the rate of $\mathrm{O}_{2}$ delivery by the capillary bed is uniformly distributed and equal to the rate of tissue $\mathrm{O}_{2}$ consumption. With these assumptions, we can derive an analytic solution to Eq. 4 that we describe below.

We generally denote the partial differential equation in cylindrical coordinates as

$$
\frac{1}{r} \frac{\partial}{\partial r}\left(r \frac{\partial p O_{2}(r)}{\partial r}\right)=\overline{\mathrm{H}}\left(\mathrm{r}-R_{\text {ves }}\right)-\overline{\mathrm{H}}\left(\mathrm{r}-R_{t}\right),
$$

where $\mathrm{pO}_{2}(r)$ is the $\mathrm{pO}_{2}$ as a function of the radial distance from the center of a diving arteriole, and $H(r)$ is a Heaviside step function $\overline{\mathrm{H}}(\mathrm{r})=\mathrm{H}(\mathrm{r}) \mathrm{CMRO}_{2} /(\mathrm{D} \alpha)$. Therefore, Eq. 5 considers three spatial regions $\mathrm{r}<R_{\text {ves }}, R_{\text {ves }} \leq \mathrm{r} \leq R_{t}$, and $\mathrm{r}>R_{t}$, where only in the middle region (e.g., for $\left.R_{\text {ves }} \leq \mathrm{r} \leq R_{t}\right)$ the right hand side of Eq. 5 is non zero. Additionally, we required that $\mathrm{pO}_{2}(\mathrm{r})$ is a continuous function at $\mathrm{r}=R_{t}$ (e.g., $\lim _{r \rightarrow R_{\mathrm{t}}^{-}} p O_{2}(r)=\lim _{r \rightarrow R_{t}^{+}} p O_{2}(r)$ ) and at $\mathrm{r}=R_{\text {ves }}$ (e.g., $\lim _{r \rightarrow R_{V e s}^{+}} \mathrm{pO}_{2}(r)=\mathrm{pO}_{2, \text { ves }}$ ) and $\quad \mathrm{a} \quad$ smooth function $\quad$ at $\quad \mathrm{r}=R_{t} \quad$ (e.g., $\left.\lim _{r \rightarrow R_{t}^{-}} \partial p O_{2}(r) / \partial r=\lim _{r \rightarrow R_{t}^{+}} \partial p O_{2}(r) / \partial r\right)$. Importantly, to better account for the $\mathrm{O}_{2}$ delivery by the capillary bed that surrounds the arteriole, we assumed that $\partial \mathrm{pO}_{2}(r) / \partial r=0$ for some $\mathrm{r}=R_{0}$, 
where $R_{\text {ves }}<R_{0} \leq R_{t}$. Finally, $\mathrm{pO}_{2}$ values that we measured at $r<R_{\text {ves }}$ did not show any diffusion gradients because they originated from extracellular dye in the tissue next to the vessel. Therefore, in our model we assumed that $\mathrm{pO}_{2}(r)_{r<R_{\text {Ves }}}=\mathrm{pO}_{2, \text { ves }}$. We considered the following solution of Eq. 5 which satisfies the above conditions:

$$
\begin{aligned}
& p O_{2}(r)_{r<R_{\text {ves }}}=p O_{2, \text { ves }} \\
& p O_{2}(r)_{R_{\text {Ves }} \leq r \leq R_{t}}=p O_{2, \text { ves }}+\frac{C M R O_{n}}{4 D a}\left(r^{2}-R_{\text {ves }}{ }^{2}-2 R_{\text {ves }}{ }^{2} \ln \frac{r}{R_{\text {ves }}}\right)+\beta \ln \frac{r}{R_{\text {ves }}} \\
& p O_{2}(r)_{r>R_{t}}=p O_{2, \text { ves }}+\frac{C M R O_{n}}{4 D a}\left(R_{t}{ }^{2}-R_{\text {ves }}{ }^{2}-2 R_{\text {ves }}{ }^{2} \ln \frac{r}{R_{\text {ves }}}+2 R_{t}{ }^{2} \ln \frac{r}{R_{t}}\right)+\beta \ln \frac{r}{R_{\text {Ves }}}
\end{aligned}
$$

This model, which we nicknamed "ODACITI", for $\mathbf{O}_{2}$ Diffusion from Arterioles and Capillaries Into TIssue, was used to fit for $\mathrm{CMRO}_{2}, \mathrm{pO}_{2_{\imath} \text { ves }}$, and $\beta$, given the arteriolar radius $R_{\text {ves }}$ and the radius of capillary-free periarteriolar space $R_{t}$. $R_{\text {ves }}$ was estimated from vascular FITC images as the full-width at half-maximum of the intensity profile drawn across the arteriole. $R_{t}$ was fixed to $80 \mu \mathrm{m}$ based on observation of the capillary bed in mice. To simplify the fitting procedure, parameter $\beta$ was used in Eqs. 6-8 to replace $C M R O_{2}\left(R_{\text {ves }}^{2}-R_{0}^{2}\right) /(2 D \alpha)$.

Notably, ODACITI model behaves not necessarily the same at $\mathrm{R}_{\mathrm{t}}$ as the original KroghErlang model given by:

$$
\mathrm{pO}_{2}(r)=\mathrm{pO}_{2, \text { ves }}+\frac{\mathrm{CMRO}_{2}}{4 D \pi}\left(r^{2}-R_{\text {ves }}^{2}-2 R_{t}^{2} \ln \frac{r}{R_{\text {Ves }}}\right)
$$

Similar to ODACITI model, this expression satisfies Eq. 4 for $R_{\text {ves }} \leq \mathrm{r} \leq R_{t}$. However, the KroghErlang model requires that $\mathrm{O}_{2}$ delivered by the vessel in the center is consumed by the tissue within the cylinder with the radius $R_{t}$, which implies that $\mathrm{O}_{2}$ flux $\left(I(r)=-D \alpha \frac{\partial p o z(r)}{\partial r}\right)$ is equal to zero at $\mathrm{r}=R_{t}$. In the Krogh-Erlang model, the expression for the $\mathrm{O}_{2}$ flux $\left(I_{K E}(r)\right)$ for $R_{\text {ves }} \leq \mathrm{r} \leq R_{t}$ is given by:

$$
I_{K E}(r)=C M R O_{2}\left(R_{t}^{2}-r^{2}\right) /(2 r)
$$


and total $\mathrm{O}_{2}$ flux through any cylindrical surface with length $\Delta z$ and radius $r$ from the vessel is equal to the product of metabolic rate of $\mathrm{O}_{2}$ and volume of the tissue that remains outside the cylinder with radius $r$ :

$$
I_{K E}(r) 2 \pi r \Delta z=C M R O_{2} \pi\left(R_{t}^{2}-r^{2}\right) \Delta z
$$

If we denote the $\mathrm{O}_{2}$ flux in ODACITI as $I_{O D}(r)$, total $\mathrm{O}_{2}$ flux through the wall of the central arteriole, for the arteriolar segment of length $\Delta z$, is given by

$$
I_{O D}\left(R_{\text {ves }}\right) 2 \pi R_{\text {ves }} \Delta z=-D \alpha \beta 2 \pi \Delta z=C M R O_{2}\left(R_{0}^{2}-R_{\text {ves }}^{2}\right) \pi \Delta z
$$

For any cylindrical surface with radius $\mathrm{r}$ between $R_{\text {ves }}$ and $R_{t}$, the total $\mathrm{O}_{2}$ flux in ODACITI is given by

$$
I_{O D}(r) 2 \pi r \Delta z=-D \alpha \beta 2 \pi \Delta z-C M R O_{2} \pi\left(r^{2}-R_{v e s}^{2}\right) \Delta z_{1}
$$

which represents a difference between the oxygen diffused from the vessel out ( $-D \alpha \beta 2 \pi \Delta z)$ and the oxygen consumed in the inner tissue cylinder $\left(\mathrm{CMRO}_{2} \pi\left(\mathrm{r}^{2}-R_{\text {ves }}{ }^{2}\right) \Delta z\right)$. Finally, total $\mathrm{O}_{2}$ flux through a cylindrical surface with $\mathrm{r}>R_{t}$ is constant:

$$
\begin{aligned}
& \operatorname{loD}(r) 2 \pi r \Delta z J(r) 2 \pi r=-D \alpha \beta_{3} 2 \pi-C M R O_{2} \pi\left(r^{2}-R_{\text {ves }}{ }^{2}\right) \\
& =-D \alpha \beta 2 \pi \Delta z-C M R O_{2} \pi\left(R_{t}{ }^{2}-R_{\text {ves }}{ }^{2}\right) \Delta z,
\end{aligned}
$$

which is in agreement with the model assumption that for $r>R_{t}, C M R O_{2}$ is exactly equal to $\mathrm{O}_{2}$ delivery rate of capillary bed. In ODACITI, if oxygen flux at $r=\mathrm{R}_{\mathrm{t}}$ is zero $\left(\operatorname{IoD}_{O D}\left(R_{t}\right)=0\right)$, then $R_{0}=R_{t}$, all oxygen delivered by the arteriole is consumed inside the $r<R_{t}$ tissue volume (e.g., $\left.-D \alpha \beta 2 \pi=\mathrm{CMRO}_{2} \pi\left(R_{t}{ }^{2}-R_{\text {ves }}{ }^{2}\right)\right)$ and ODACITI scales back exactly to the Krogh-Erlang model with additions that $\mathrm{pO}_{2}=$ const for $r<R_{\text {ves }}$ and $r>R_{t}$. However, in ODACITI it is possible that the radius where $I_{O D}(r)=0$ can be smaller than $R_{t}$, which can better account for the influence of the capillary bed. In addition, this model allows to include more measured data points from small 
$\left(r<R_{\text {ves }}\right)$ and large radii $\left(r>R_{t}\right)$ into the fitting procedures as compared to using the Krogh-Erlang model.

\section{Segmentation of regions of interest}

ODACITI describes $\mathrm{pO}_{2}$ gradients around diving arterioles for an ideal case of radial symmetry. In practice, however, capillary geometry around diving cortical arterioles is not perfectly radially symmetric. The model also assumes that $\mathrm{pO}_{2}$ decreases monotonically with increasing radial distance from the arteriole until reaching a certain stable level within the capillary bed. In reality, however, at certain distance $\mathrm{pO}_{2}$ may increase again due to presence of another highly oxygenated blood vessel that can be (a branch of) a diving arteriole or a postarteriolar capillary. To mitigate this issue, we devised an algorithm for automated segmentation of a region of interest $(\mathrm{ROI})$ for each acquired $\mathrm{pO}_{2}$ grid. First, tissue $\mathrm{pO}_{2}$ measurements were co-registered with the vascular anatomical images to localize the center of the arteriole. Next, 20 equally spaced radii were drawn in the territory around a center arteriole and a $\mathrm{pO}_{2}$ vector was interpolated as a function of the radial distance from the arteriole. These vectors were spatially filtered using the cubic smoothing spline csaps MATLAB function with smoothing parameter $p=0.001$ to reduce the effect of noise in the measurements. For each vector, we calculated the first spatial derivative $\frac{d p O_{2}}{d r}$ and included all $\mathrm{pO}_{2}$ data points with radii where $\frac{d p O_{2}}{d r}>0$. Finally, we added all $\mathrm{pO}_{2}$ measurements within the low $35 \%$ tail of each $\mathrm{pO}_{2}$ map to include capillary bed data points. Taken together, these steps resulted in exclusion of data points around additional oxygen sources within the capillary bed deviant from the model assumptions. Included $\mathrm{pO}_{2}$ data were then collapsed to generate a radial gradient for estimation of $\mathrm{CMRO}_{2}$ with the ODACITI model for each peri-arteriolar grid. When multiple acquisitions of the same plane were available, $\mathrm{CMRO}_{2}$ estimates were averaged. 


\section{Synthetic data}

To validate estimation of $\mathrm{CMRO}_{2}$ using ODACITI, we generated synthetic $\mathrm{pO}_{2}$ data by solving the Poisson equation for a given (space-invariant) value of $\mathrm{CMRO}_{2}$ and chosen geometry of vascular sources and measurements points. This was done numerically using the finite element software package FEniCS (Logg et al 2012) as described in our recent publication (Saetra et al 2020). Briefly, we solve the variational formulation of the Poisson equation where $\mathrm{CMRO}_{2}$ is constant, intravascular $\mathrm{pO}_{2}$ is fixed, and there is no pressure gradient at the vessel wall boundary. Then, if $V$ is a space of test functions $\left[v_{1}, \ldots v_{N}\right]$ on the computational domain $\Omega$, we can find $\mathrm{pO}_{2}$ such that $\int_{\Omega} \nabla p \mathrm{O}_{2} * V v_{i}$ is equal to $\mathrm{CMRO}_{2}$ scaled by a number that depends on the test function $v_{i}$. FEniCS provides the solution on an unstructured finite element mesh. Experimental data, in contrast, are measured on a Cartesian grid. Therefore, we transferred the synthetic data generated by FEniCS to a Cartesian grid similar to that used in our experiments. Additive Gaussian noise was implemented using the normrnd MATLAB function. For each synthetic data point in the grid, we drew a random number from a Gaussian distribution with the $\mathrm{pO}_{2}$ value at this point as the mean $(\mu)$ and standard deviation of $\sigma=2$. Afterwards, we replaced the $\mathrm{pO}_{2}$ value by $(\mu+\sigma)$.

\section{Statistics}

Statistical analysis was performed using The R Project for Statistical Computing (www.rproject.org) using a linear mixed-effect model implemented in the Ime4 package, where trends observed within a subject (e.g., the dependence of $\mathrm{CMRO}_{2}$ on depth) were treated as fixed effects, while the variability between subjects was considered as a random effect. Observations within an animal subject were considered dependent; observations between subjects, independent. 


\section{Figure Legends}

Figure 1. Measurements of tissue $\mathrm{pO}_{2}$ across cortical layers of awake mice using 2photon phosphorescence lifetime microscopy (2PLM)

A. Imaging setup for 2PLM in awake, head-restrained mice. Ti:sapph (80 MHz) - femtosecond pulsed laser tuned to $950 \mathrm{~nm}$; EOM - electro-optic modulator; D900LP and D660LP- long pass dichroic mirrors with a cutoff at 900 and $660 \mathrm{~nm}$, respectively; GaAsP - photomultiplier tubes; 900SP and 945SP - short pass optical filters with a cutoff at 900 and $945 \mathrm{~nm}$, respectively; Em525/70, Em617/70, Em736/128 - bandpass emission filters. The inset in the lower right corner illustrates a phosphorescence decay; data (black) and fit (red) are overlaid.

B. Schematics of the chronic cranial window with a silicon port for intracortical injection of Oxyphor 2P.

C. An image of surface vasculature calculated as a maximum intensity projection (MIP) of a 2photon image stack 0-300 $\mu \mathrm{m}$ in depth using a 5x objective. Individual images were acquired every $10 \mu \mathrm{m}$. Fluorescence is due to intravascular FITC.

D. An example set of images tracking a diving arteriole throughout the top $500 \mu \mathrm{m}$ of cortex (red arrows). Fluorescence is due to intravascular FITC.

E. A measurement plane $200 \mu \mathrm{m}$ deep including intravascular FITC (left) and SR101-labeled astrocytes (right) for the same arteriole as in (D). Scale bar $=50 \mu \mathrm{m}$

G. Histogram of $\mathrm{pO}_{2}$ values corresponding to $(\mathrm{F})$.

F. A square measurement grid of $20 \times 20$ points obtained from the imaging plane shown in (E). Left: photon counts are overlaid on the image of phosphorescence. Right: calculated $\mathrm{pO}_{2}$ values superimposed on a vascular FITC image. Scale bar $=50 \mu \mathrm{m}$

H. $\mathrm{pO}_{2}$ histograms across cortical layers. Each panel shows overlaid histograms from each measurement plane (gray) and superimposed average (red). 
I. Quantification of the top and bottom $35 \%$ of the $\mathrm{pO}_{2}$ distributions from $(\mathrm{H})$. Error bars show standard error calculated using a mixed effect model implemented in $R$ ( $p>0.1$ for the top $35 \%$ and $\mathrm{p}<0.05$ for the bottom $35 \%)$.

\section{Figure 2. ODACITI model and validation with synthetic data}

A. Schematic illustration of the model assumptions. The center arteriole is the only source of $\mathrm{O}_{2}$ for the pink peri-arteriolar region void of capillaries extending out to radius $r=R_{t}$. For $r>R_{t}$, delivery and consumption are balanced.

B. Comparison of the functional form of the Krogh-Erlang (black) and ODACITI model (green). The Krogh-Erlang model but not ODACITI forces an increase in $\mathrm{pO}_{2}$ beyond $\mathrm{R}_{\mathrm{t}}$.

C. Application of ODACITI to synthetic data with added Gaussian noise $(\sigma=2)$. In these data, $p_{2}=P_{\text {ves }}$ for $r<R_{\text {ves }}$ and $p O_{2}=p_{2}\left(R_{t}\right)$ for $r>R_{t}$. For $R_{v e s}<r<R_{t}$, we solved for $p O_{2}$ using the Krogh-Erlang equation. Three cases with $\mathrm{CMRO}_{2}$ of 1,2 and $3 \mu \mathrm{mol} \mathrm{cm}-3$ min-1 (color-coded) are superimposed. The ODACITI fit (lines) are overlaid on the data (points).

D. Simulated $\mathrm{pO}_{2}$ data generated by solving the Poisson equation in $2 \mathrm{D}$ for a given geometry of vascular $\mathrm{O}_{2}$ sources, including one highly oxygenated vessel (on the right) and given $\mathrm{CMRO}_{2}=2$ $\mu \mathrm{mol} \mathrm{cm}-3 \mathrm{~min}-1$.

E. The $\mathrm{pO}_{2}$ gradient as a function of the distance from the center arteriole. The green line shows ODACITI fit.

F. As in (E) after adding Gaussian noise ( $\sigma=2 \mathrm{SD})$.

Figure 3. $\mathrm{CMRO}_{2}$ estimation across cortical layers

A. An imaging plane $100 \mu \mathrm{m}$ below the surface; a grid of $\mathrm{pO}_{2}$ points is overlaid on the vascular image. $\mathrm{pO}_{2}$ values were interpolated along the radial yellow lines. The yellow shaded area extends along each direction until the first derivative becomes zero. Segmented ROI used for 
extraction of the radial $\mathrm{pO}_{2}$ profile is shown on the right. This $\mathrm{ROI}$ includes in addition values within the low tail of the $\mathrm{pO}_{2}$ distribution.

B. The radial $\mathrm{pO}_{2}$ profile extracted from (A). ODACITI fit is overlaid on the data. The fitted $\mathrm{CMRO}_{2}$ value is $1.5 \mu \mathrm{mol} \mathrm{cm} \mathrm{min}^{-1}$.

C. Estimated $\mathrm{CMRO}_{2}$ for the entire dataset of 24 planes along 6 diving arterioles in 4 subjects. Measurements along the same arteriole are connected in a line. Subjects are color-coded.

D. Quantification of $\mathrm{CMRO}_{2}$ across layers using the data in (C). Error bars show standard error calculated using a linear mixed effect model implemented in $R$.

E. Superimposed color-coded grand averaged radial $\mathrm{pO}_{2}$ profiles for layers I, II/III and IV (mean \pm SEM for $5-\mu \mathrm{m}$ bins). For each layer, the profile was obtained by averaging all measurements within that layer across arterioles and subjects.

F. $\mathrm{CMRO}_{2}$ extracted from averaged profiles in (E).

\section{Supplementary Figure 1. Optical window with a silicon access port}

A. Top view of the window before filling the injection port with silicon. There are three 3-mm glass coverslips stacked together and glued to a $5-\mathrm{mm}$ glass coverslip. The $3-\mathrm{mm}$ stack is beveled to guide the pipette at an angle through the port.

B. A side view of the window; the port is filled with silicon.

C. A top view of an implanted window; surface blood vessels are visible under the glass.

D. An image of surface vasculature within the same window calculated as a maximum intensity projection (MIP) of a 2-photon image stack 0-300 $\mu \mathrm{m}$ in depth using a 5x objective. Individual images were acquired every $10 \mu \mathrm{m}$. Fluorescence is due to intravascular FITC.

E. Consecutive images obtained 43 days apart demonstrate stability of surface vasculature overtime.

\section{Supplementary Figure 2. Example dataset for one arteriole across depths}


A. Intravascular FITC images for six imaging planes (cortical surface, $100 \mu \mathrm{m}, 200 \mu \mathrm{m}, 300 \mu \mathrm{m}$, $350 \mu \mathrm{m}, 400 \mu \mathrm{m})$. Arrows point to a diving arteriole that branches into two between 100 and 200 $\mu \mathrm{m}$.

B. Phosphorescence images for each of these planes.

C. SR101 images; for two of the planes SR101 images were not acquired.

D. A square measurement grid of $20 \times 20$ points for each of the imaging planes. Photon counts are superimposed on corresponding vascular FITC images.

E. Calculated $\mathrm{pO}_{2}$ values superimposed on corresponding vascular FITC images.

\section{Supplementary Figure 3. The effect of $R_{t}$ on $\mathrm{CMRO}_{2}$ estimates}

A. Synthetic $\mathrm{pO}_{2}$ data based on the Krogh-Erlang model $\left(\mathrm{CMRO}_{2}=2 \mu \mathrm{mol} \mathrm{cm}-3 \mathrm{~min}-1, \mathrm{R}_{\mathrm{t}}=80\right.$

$\left.\mu \mathrm{m}, \mathrm{P}_{\mathrm{ves}}=60 \mathrm{mmHg}, \mathrm{R}_{\mathrm{ves}}=10 \mu \mathrm{m}\right)$ are plotted against the distance from the arteriole. A constant $\mathrm{pO}_{2}$ is assumed for $\mathrm{r}>\mathrm{R}_{\mathrm{t}}$.

B. The estimated $\mathrm{CMRO}_{2}$ after applying ODACITI (green) and the Krogh-Erlang model (black) on the synthetic data in panel $A$ as a function of different assumed $R_{t}$ values (the true $R_{t}=80$ $\mu \mathrm{m})$.

\section{Supplementary Figure 4. $\mathrm{pO}_{2}$ measurements at the cortical surface}

A. Intravascular FITC image of a small surface arteriole (left) and a corresponding phosphorescence image (right).

B. A square measurement grid overlaid on the FITC image from (A). Left: photon counts. Right: calculated $\mathrm{pO}_{2}$ values. Scale bar $=50 \mu \mathrm{m}$

C. Histogram of $\mathrm{pO}_{2}$ values corresponding to (B).

D. Overlaid histograms from each surface measurement plane (corresponding to individual arterioles, gray) and superimposed average (red). 


\section{Supplementary Figure 5. Cumulative radial $\mathrm{pO}_{2}$ profiles for each layer}

A. All data points included in the $\mathrm{CMRO}_{2}$ estimation in Figure 3; the mean (calculated using 2.5 $\mu \mathrm{m}$ binning) is superimposed in thick black.

B. The same as (A) for layer II/III.

C. The same as (A) for layer IV.

\section{Supplementary Figure 6. Accuracy of $\mathrm{pO}_{2}$ estimation as a function of number of excitation cycles}

A. Left: an imaging plane $100 \mu \mathrm{m}$ below the surface. Fluorescence is due to intravascular FITC. Middle: a grid of measurement points overlaid on the FITC image. Right: photon count overlaid on the FITC image.

B. $\mathrm{pO}_{2}$ values overlaid on the FITC image from (A).

C. Phosphorescence decays for two points labeled in (B). Data (points) and fit (lines) are overlaid. Lower $\mathrm{pO}_{2}$ corresponds to slower decay (blue).

D. Residual error over time.

E. The squared residual norm (output of Isqnonlin) plotted against the number of excitation cycles that were used to sum the photon counts. 


\section{References}

Attwell D, Laughlin SB. 2001. An energy budget for signaling in the grey matter of the brain. $J$ Cereb Blood Flow Metab 21: 1133-45

Blinder P, Tsai PS, Kaufhold JP, Knutsen PM, Suhl H, Kleinfeld D. 2013. The cortical angiome: an interconnected vascular network with noncolumnar patterns of blood flow. Nat Neurosci 16: 889-97

Buxton RB. 2010. Interpreting oxygenation-based neuroimaging signals: the importance and the challenge of understanding brain oxygen metabolism. Front Neuroenergetics 2: 8

Cheng X, Sadegh S, Zilpelwar S, Devor A, Tian L, Boas DA. 2020. Comparing the fundamental imaging depth limit of two-photon, three-photon, and non-degenerate two-photon microscopy. Opt Lett 45: 2934-37

Desjardins M, Kilic K, Thunemann M, Mateo C, Holland D, et al. 2019. Awake Mouse Imaging: From Two-Photon Microscopy to Blood Oxygen Level-Dependent Functional Magnetic Resonance Imaging. Biol Psychiatry Cogn Neurosci Neuroimaging 4: 533-42

Devor A, Boas D, Einevoll GT, Buxton RB, Dale AM. 2012a. Neuronal Basis of Non-Invasive Functional Imaging: From Microscopic Neurovascular Dynamics to BOLD fMRI In Neural Metabolism In Vivo, ed. RG In-Young Choi. New York: Springer

Devor A, Sakadzic S, Saisan PA, Yaseen MA, Roussakis E, et al. 2011. "Overshoot" of O(2) is required to maintain baseline tissue oxygenation at locations distal to blood vessels. $J$ Neurosci 31: 13676-81

Devor A, Sakadzic S, Srinivasan VJ, Yaseen MA, Nizar K, et al. 2012b. Frontiers in optical imaging of cerebral blood flow and metabolism. J Cereb Blood Flow Metab 32: 1259-76

Devor A, Sakadzic S, Yaseen MA, Roussakis E, Tian P, et al. 2013. Functional imaging of cerebral oxygenation with intrinsic optical contrast and phosphorescent probes In Optical imaging of cortical circuit dynamics, ed. B Weber, F Helmchen. New York: Springer 
Dienel GA. 2019. Brain Glucose Metabolism: Integration of Energetics with Function. Physiol Rev 99: 949-1045

Dienel GA, Cruz NF. 2016. Aerobic glycolysis during brain activation: adrenergic regulation and influence of norepinephrine on astrocytic metabolism. J Neurochem 138: 14-52

Dumoulin SO, Fracasso A, van der Zwaag W, Siero JCW, Petridou N. 2018. Ultra-high field MRI: Advancing systems neuroscience towards mesoscopic human brain function. Neuroimage 168: 345-57

Dunn AK, Devor A, Dale AM, Boas DA. 2005. Spatial extent of oxygen metabolism and hemodynamic changes during functional activation of the rat somatosensory cortex. Neuroimage 27: 279-90

Engl E, Attwell D. 2015. Non-signalling energy use in the brain. J Physiol 593: 3417-29

Esipova TV, Barrett MJP, Erlebach E, Masunov AE, Weber B, Vinogradov SA. 2019. Oxyphor 2P: A High-Performance Probe for Deep-Tissue Longitudinal Oxygen Imaging. Cell Metab 29: 736-44 e7

Feldmeyer D, Brecht M, Helmchen F, Petersen CC, Poulet JF, et al. 2013. Barrel cortex function. Prog Neurobiol 103: 3-27

Feng J, Zhang C, Lischinsky JE, Jing M, Zhou J, et al. 2019. A Genetically Encoded Fluorescent Sensor for Rapid and Specific In Vivo Detection of Norepinephrine. Neuron 102: $745-61$ e8

Finikova OS, Lebedev AY, Aprelev A, Troxler T, Gao F, et al. 2008. Oxygen microscopy by twophoton-excited phosphorescence. Chemphyschem 9: 1673-9

Gagnon L, Sakadzic S, Lesage F, Musacchia JJ, Lefebvre J, et al. 2015. Quantifying the microvascular origin of BOLD-fMRI from first principles with two-photon microscopy and an oxygen-sensitive nanoprobe. J Neurosci 35: 3663-75

Goense J, Bohraus Y, Logothetis NK. 2016. fMRI at High Spatial Resolution: Implications for BOLD-Models. Front Comput Neurosci 10: 66 
Goense J, Merkle H, Logothetis NK. 2012. High-resolution fMRI reveals laminar differences in neurovascular coupling between positive and negative BOLD responses. Neuron 76: 629-39

Goldman D. 2008. Theoretical models of microvascular oxygen transport to tissue. Microcirculation 15: 795-811

Griffeth VE, Perthen JE, Buxton RB. 2011. Prospects for quantitative fMRI: investigating the effects of caffeine on baseline oxygen metabolism and the response to a visual stimulus in humans. Neuroimage 57: 809-16

Harris KD, Shepherd GM. 2015. The neocortical circuit: themes and variations. Nat Neurosci 18: 170-81

Helmstaedter M, de Kock CP, Feldmeyer D, Bruno RM, Sakmann B. 2007. Reconstruction of an average cortical column in silico. Brain Res Rev 55: 193-203

Hirano Y, Stefanovic B, Silva AC. 2011. Spatiotemporal evolution of the functional magnetic resonance imaging response to ultrashort stimuli. J Neurosci 31: 1440-7

Hyder F, Rothman DL, Bennett MR. 2013. Cortical energy demands of signaling and nonsignaling components in brain are conserved across mammalian species and activity levels. Proc Natl Acad Sci U S A 110: 3549-54

Kasischke KA, Lambert EM, Panepento B, Sun A, Gelbard HA, et al. 2011. Two-photon NADH imaging exposes boundaries of oxygen diffusion in cortical vascular supply regions. $J$ Cereb Blood Flow Metab 31: 68-81

Kilic K, Desjardins M, Tang J, Thunemann M, Sunil S, et al. 2020. Chronic Cranial Windows for Long Term Multimodal Neurovascular Imaging in Mice. Front Physiol 11: 612678

Krogh A. 1919. The number and distribution of capillaries in muscles with calculations of the oxygen pressure head necessary for supplying the tissue. J Physiol 52: 409-15

Land PW, Simons DJ. 1985. Cytochrome oxidase staining in the rat Sml barrel cortex. J Comp Neurol 238: 225-35 
Lecoq J, Parpaleix A, Roussakis E, Ducros M, Goulam Houssen Y, et al. 2011. Simultaneous two-photon imaging of oxygen and blood flow in deep cerebral vessels. Nat Med 17: $893-8$

Li B, Esipova TV, Sencan I, Kilic K, Fu B, et al. 2019. More homogeneous capillary flow and oxygenation in deeper cortical layers correlate with increased oxygen extraction. Elife 8

Logg A, Mardal K-A, Wells G. 2012. Automated solution of differential equations by the finite 542 element method: The FEniCS book. Springer Science \& Business Media.

Lu X, Moeini M, Li B, de Montgolfier O, Lu Y, et al. 2020. Voluntary exercise increases brain tissue oxygenation and spatially homogenizes oxygen delivery in a mouse model of Alzheimer's disease. Neurobiol Aging 88: 11-23

Lyons DG, Parpaleix A, Roche M, Charpak S. 2016. Mapping oxygen concentration in the awake mouse brain. Elife 5

Machler P, Broggini T, Mateo C, Thunemann M, Fomin-Thunemann N, et al. 2021. A Suite of Neurophotonic Tools to Underpin the Contribution of Internal Brain States in fMRI. Curr Opin Biomed Eng 18

Madsen PL, Schmidt JF, Wildschiodtz G, Friberg L, Holm S, et al. 1991. Cerebral O2 metabolism and cerebral blood flow in humans during deep and rapid-eye-movement sleep. J Appl Physiol (1985) 70: 2597-601

Markram H, Toledo-Rodriguez M, Wang Y, Gupta A, Silberberg G, Wu C. 2004. Interneurons of the neocortical inhibitory system. Nat Rev Neurosci 5: 793-807

Moeini M, Lu X, Belanger S, Picard F, Boas D, et al. 2019. Cerebral tissue pO2 response to stimulation is preserved with age in awake mice. Neurosci Lett 699: 160-66

Perthen JE, Lansing AE, Liau J, Liu TT, Buxton RB. 2008. Caffeine-induced uncoupling of cerebral blood flow and oxygen metabolism: a calibrated BOLD fMRI study. Neuroimage 40: $237-47$ 
Podgorski K, Ranganathan G. 2016. Brain heating induced by near-infrared lasers during multiphoton microscopy. J Neurophysiol 116: 1012-23

Polimeni JR, Fischl B, Greve DN, Wald LL. 2010. Laminar analysis of 7T BOLD using an imposed spatial activation pattern in human V1. Neuroimage 52: 1334-46

Polimeni JR, Wald LL. 2018. Magnetic Resonance Imaging technology-bridging the gap between noninvasive human imaging and optical microscopy. Curr Opin Neurobiol 50: $250-60$

Raichle ME, Mintun MA. 2006. Brain work and brain imaging. Annu Rev Neurosci 29: 449-76

Roche M, Chaigneau E, Rungta RL, Boido D, Weber B, Charpak S. 2019. In vivo imaging with a water immersion objective affects brain temperature, blood flow and oxygenation. Elife 8

Roome CJ, Kuhn B. 2014. Chronic cranial window with access port for repeated cellular manipulations, drug application, and electrophysiology. Front Cell Neurosci 8: 379

Royl G, Fuchtemeier M, Leithner C, Megow D, Offenhauser N, et al. 2008. Hypothermia effects on neurovascular coupling and cerebral metabolic rate of oxygen. Neuroimage 40: 152332

Rupprecht P, Prevedel R, GroessI F, Haubensak WE, Vaziri A. 2015. Optimizing and extending light-sculpting microscopy for fast functional imaging in neuroscience. Biomed Opt Express 6: 353-68

Sabatini BL, Tian L. 2020. Imaging Neurotransmitter and Neuromodulator Dynamics In Vivo with Genetically Encoded Indicators. Neuron 108: 17-32

Sadegh S, Yang MH, Ferri CGL, Thunemann M, Saisan PA, et al. 2019. Efficient nondegenerate two-photon excitation for fluorescence microscopy. Opt Express 27: 2802235

Saetra MJ, Solbra AV, Devor A, Sakadzic S, Dale AM, Einevoll GT. 2020. Spatially resolved estimation of metabolic oxygen consumption from optical measurements in cortex. Neurophotonics 7: 035005 
Sakadzic S, Mandeville ET, Gagnon L, Musacchia JJ, Yaseen MA, et al. 2014. Large arteriolar component of oxygen delivery implies a safe margin of oxygen supply to cerebral tissue. Nat Commun 5: 5734

Sakadzic S, Roussakis E, Yaseen MA, Mandeville ET, Srinivasan VJ, et al. 2010. Two-photon high-resolution measurement of partial pressure of oxygen in cerebral vasculature and tissue. Nat Methods 7: 755-9

Sakadzic S, Yaseen MA, Jaswal R, Roussakis E, Dale AM, et al. 2016. Two-photon microscopy measurement of cerebral metabolic rate of oxygen using periarteriolar oxygen concentration gradients. Neurophotonics 3: 045005

Santuy A, Turegano-Lopez M, Rodriguez JR, Alonso-Nanclares L, DeFelipe J, Merchan-Perez A. 2018. A Quantitative Study on the Distribution of Mitochondria in the Neuropil of the Juvenile Rat Somatosensory Cortex. Cerebral cortex 28: 3673-84

Sencan I, Esipova T, Kilic K, Li B, Desjardins M, et al. 2020. Optical measurement of microvascular oxygenation and blood flow responses in awake mouse cortex during functional activation. J Cereb Blood Flow Metab: 271678X20928011

Siero JC, Hendrikse J, Hoogduin H, Petridou N, Luijten P, Donahue MJ. 2015. Cortical depth dependence of the BOLD initial dip and poststimulus undershoot in human visual cortex at 7 Tesla. Magn Reson Med 73: 2283-95

Srinivasan VJ, Radhakrishnan H. 2014. Optical Coherence Tomography angiography reveals laminar microvascular hemodynamics in the rat somatosensory cortex during activation. Neuroimage 102 Pt 2: 393-406

Theer P, Denk W. 2006. On the fundamental imaging-depth limit in two-photon microscopy. $J$ Opt Soc Am A Opt Image Sci Vis 23: 3139-49

Turner R. 2016. Uses, misuses, new uses and fundamental limitations of magnetic resonance imaging in cognitive science. Philos Trans R Soc Lond B Biol Sci 371 
Ugurbil K. 2018. Imaging at ultrahigh magnetic fields: History, challenges, and solutions. Neuroimage 168: 7-32

Uhlirova H, Kilic K, Tian P, Sakadzic S, Gagnon L, et al. 2016a. The roadmap for estimation of cell-type-specific neuronal activity from non-invasive measurements. Philos Trans $R$ Soc Lond B Biol Sci 371

Uhlirova H, Kilic K, Tian P, Thunemann M, Desjardins M, et al. 2016b. Cell type specificity of neurovascular coupling in cerebral cortex. Elife 5

Wald LL. 2012. The future of acquisition speed, coverage, sensitivity, and resolution. Neuroimage 62: 1221-9

Weber B, Keller AL, Reichold J, Logothetis NK. 2008. The microvascular system of the striate and extrastriate visual cortex of the macaque. Cerebral cortex 18: 2318-30

Wong-Riley MT. 1989. Cytochrome oxidase: an endogenous metabolic marker for neuronal activity. Trends in neurosciences 12: 94-101

Woolsey TA, Van der Loos H. 1970. The structural organization of layer IV in the somatosensory region (SI) of mouse cerebral cortex. The description of a cortical field composed of discrete cytoarchitectonic units. Brain Res 17: 205-42

Wu J, Guo C, Chen S, Jiang T, He Y, et al. 2016. Direct 3D Analyses Reveal Barrel-Specific Vascular Distribution and Cross-Barrel Branching in the Mouse Barrel Cortex. Cerebral cortex 26: 23-31

Yellen G. 2018. Fueling thought: Management of glycolysis and oxidative phosphorylation in neuronal metabolism. J Cell Biol 217: 2235-46

Yu X, Qian C, Chen DY, Dodd SJ, Koretsky AP. 2014. Deciphering laminar-specific neural inputs with line-scanning fMRI. Nat Methods 11: 55-8

Zhang Q, Roche M, Gheres KW, Chaigneau E, Kedarasetti RT, et al. 2019. Cerebral oxygenation during locomotion is modulated by respiration. Nat Commun 10: 5515 
bioRxiv preprint doi: https://doi.org/10.1101/2021.10.13.464176; this version posted October 14, 2021. The copyright holder for this preprint (which was not certified by peer review) is the author/funder, who has granted bioRxiv a license to display the preprint in perpetuity. It is made available under aCC-BY 4.0 International license.

Zuend M, Saab AS, Wyss MT, Ferrari KD, Hösli L, et al. 2020. Arousal-induced cortical activity triggers lactate release from astrocyt. Nature Metabolism 2: 179-91 
bioRxiv preprint doi: https://doi.org/10.1101/2021.10.13.464176; this version posted October 14, 2021. The copyright holder for this preprint (which was not certified by peer review) is the author/funder, who has granted bioRxiv a license to display the preprint in perpetuity. It is made available under aCC-BY 4.0 International license.

\section{Figure 1}

A

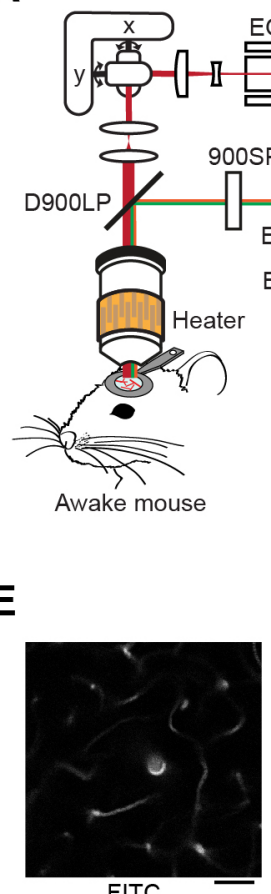

H

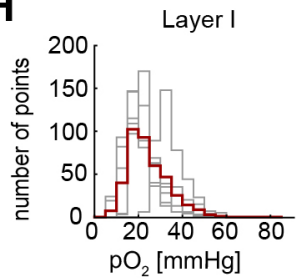

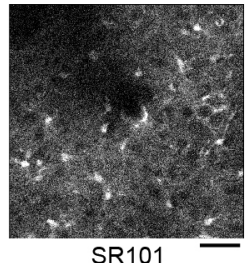

Layer II/III
$\mathbf{F}$

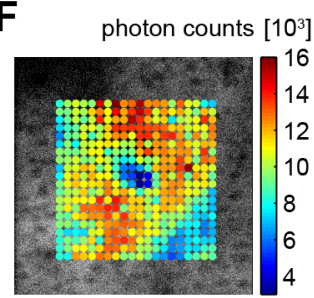

Oxyphor 2P

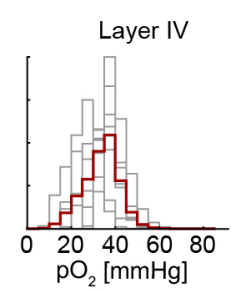

B
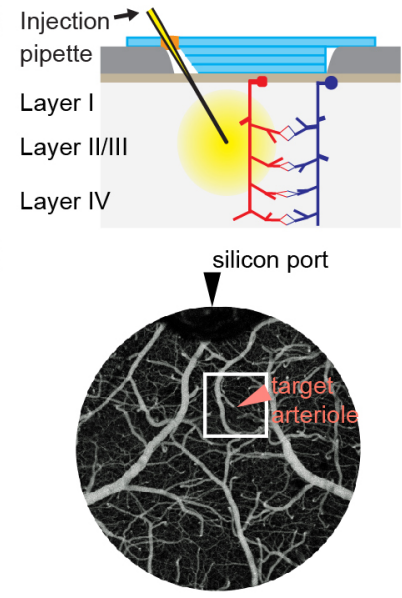

$\mathrm{pO}_{2}[\mathrm{mmHgl}$

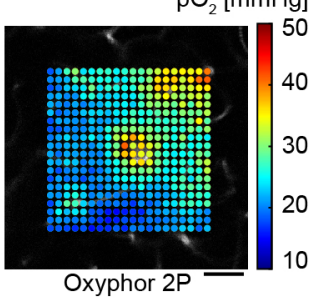

I
D

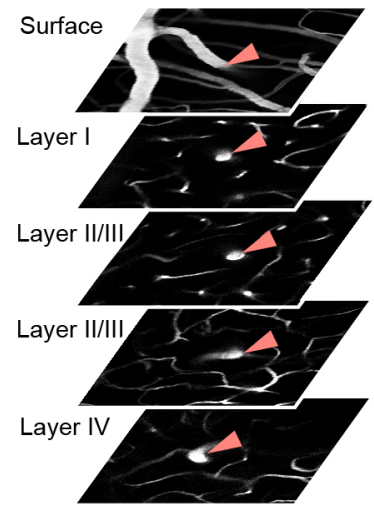

G
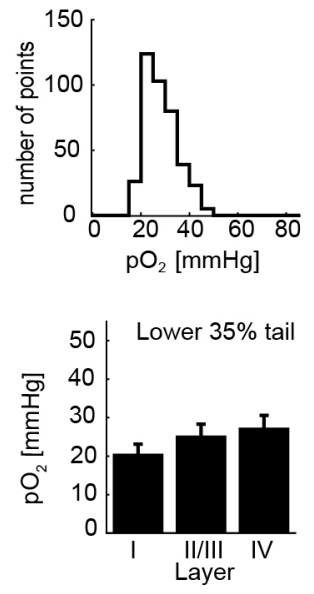
bioRxiv preprint doi: https://doi.org/10.1101/2021.10.13.464176; this version posted October 14, 2021. The copyright holder for this preprint (which was not certified by peer review) is the author/funder, who has granted bioRxiv a license to display the preprint in perpetuity. It is made available under aCC-BY 4.0 International license.

\section{Figure 2}
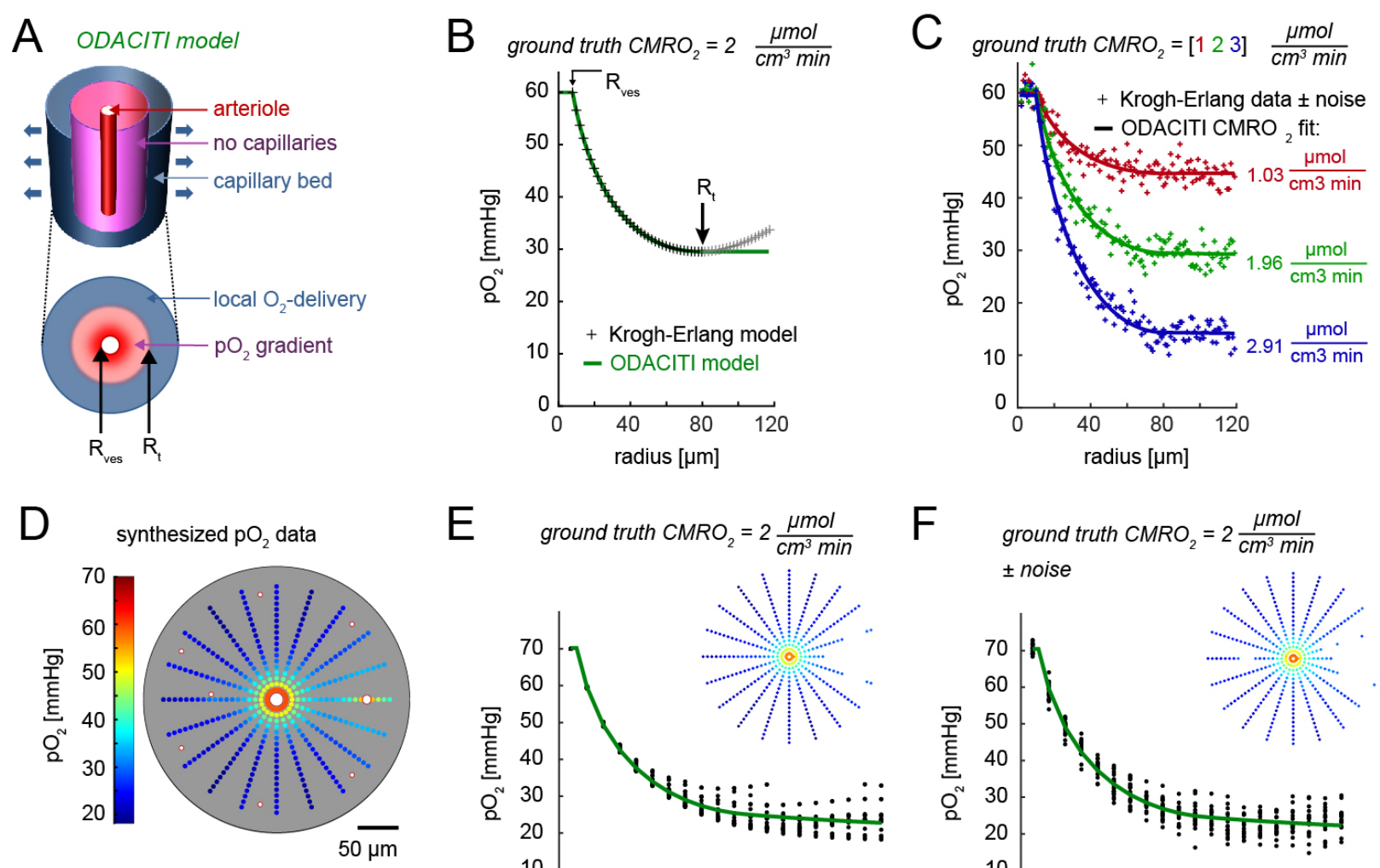

$E$

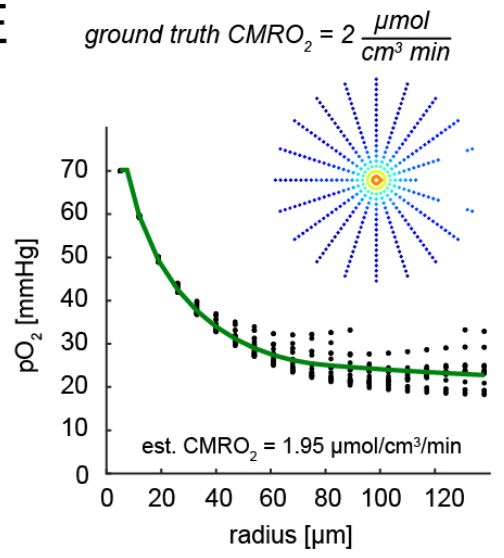

$\mathrm{F}$

ground truth $\mathrm{CMRO}_{2}=2 \frac{\mu \mathrm{mol}}{\mathrm{cm}^{3} \mathrm{~min}}$ \pm noise

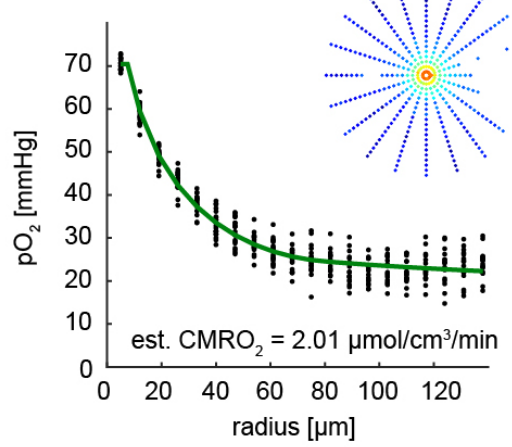


bioRxiv preprint doi: https://doi.org/10.1101/2021.10.13.464176; this version posted October 14,2021 . The copyright holder for this preprint (which was not certified by peer review) is the author/funder, who has granted bioRxiv a license to display the preprint in perpetuity. It is made available under aCC-BY 4.0 International license.

Figure 3
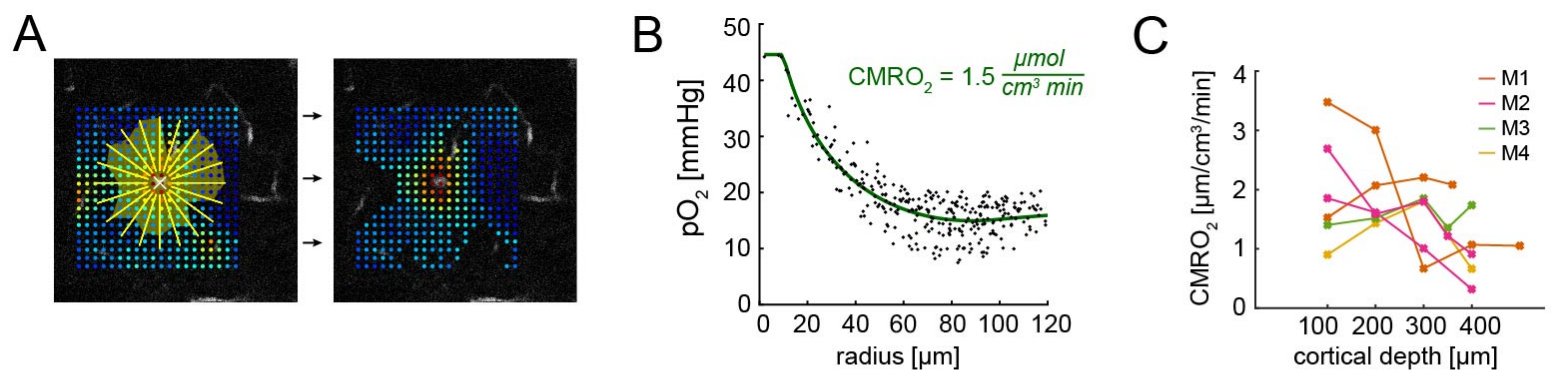

D

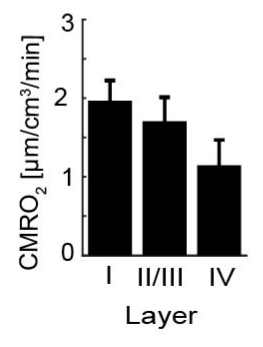

E

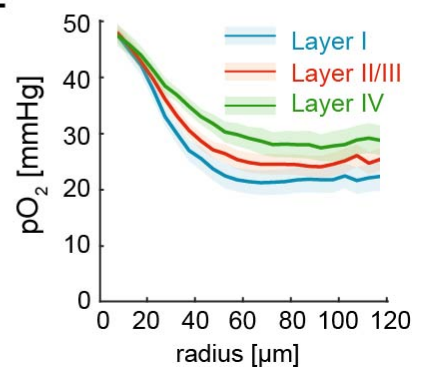

F

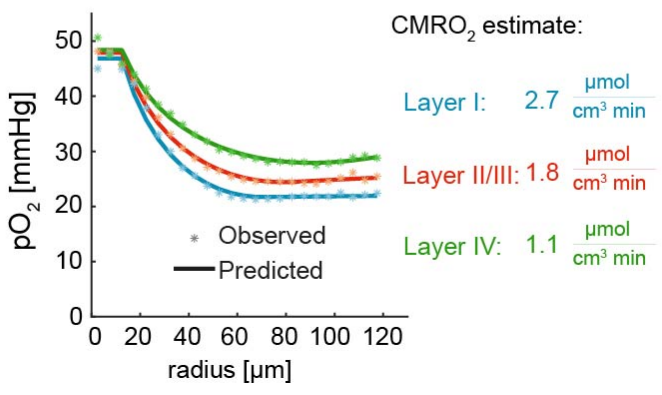


bioRxiv preprint doi: https://doi.org/10.1101/2021.10.13.464176; this version posted October 14,2021 . The copyright holder for this preprint (which was not certified by peer review) is the author/funder, who has granted bioRxiv a license to display the preprint in perpetuity. It is made available under aCC-BY 4.0 International license.

\section{Supplementary Figure 1}

A

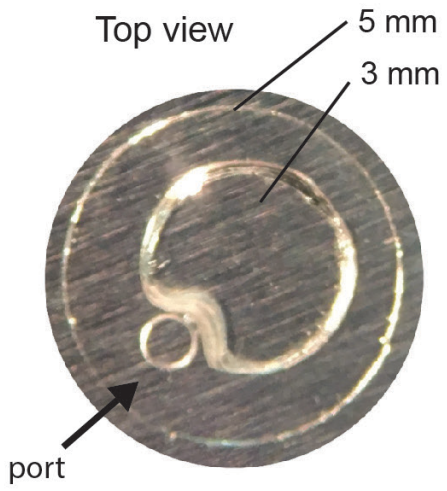

C

Bright field

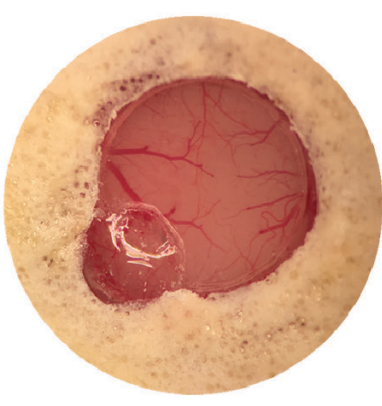

E

Day 13

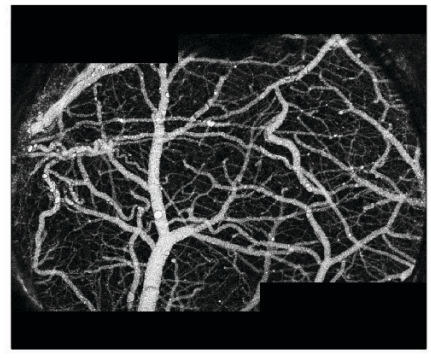

B

Side view

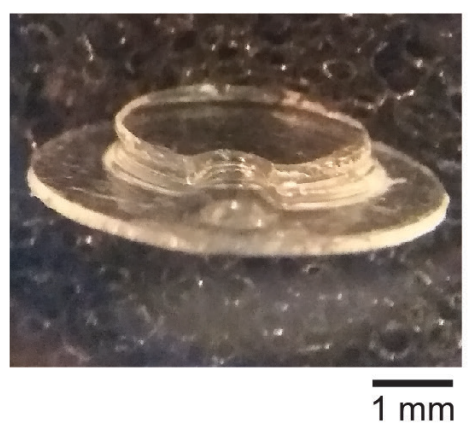

D

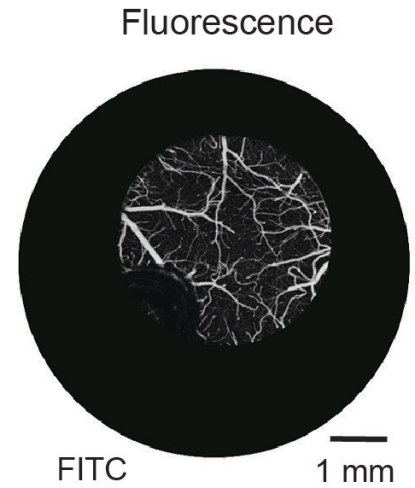

$\mathrm{F}$

Day 56

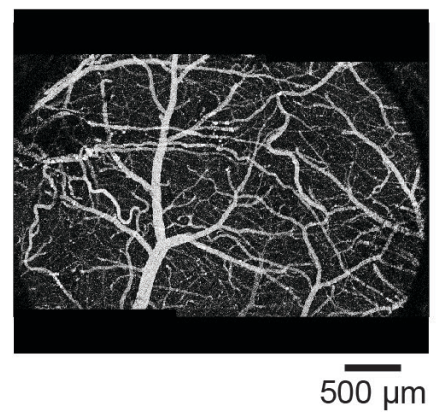


bioRxiv preprint doi: https://doi.org/10.1101/2021.10.13.464176; this version posted October 14, 2021. The copyright holder for this preprint (which was not certified by peer review) is the author/funder, who has granted bioRxiv a license to display the preprint in perpetuity. It is made available under aCC-BY 4.0 International license.

\section{Supplementary Figure 2}
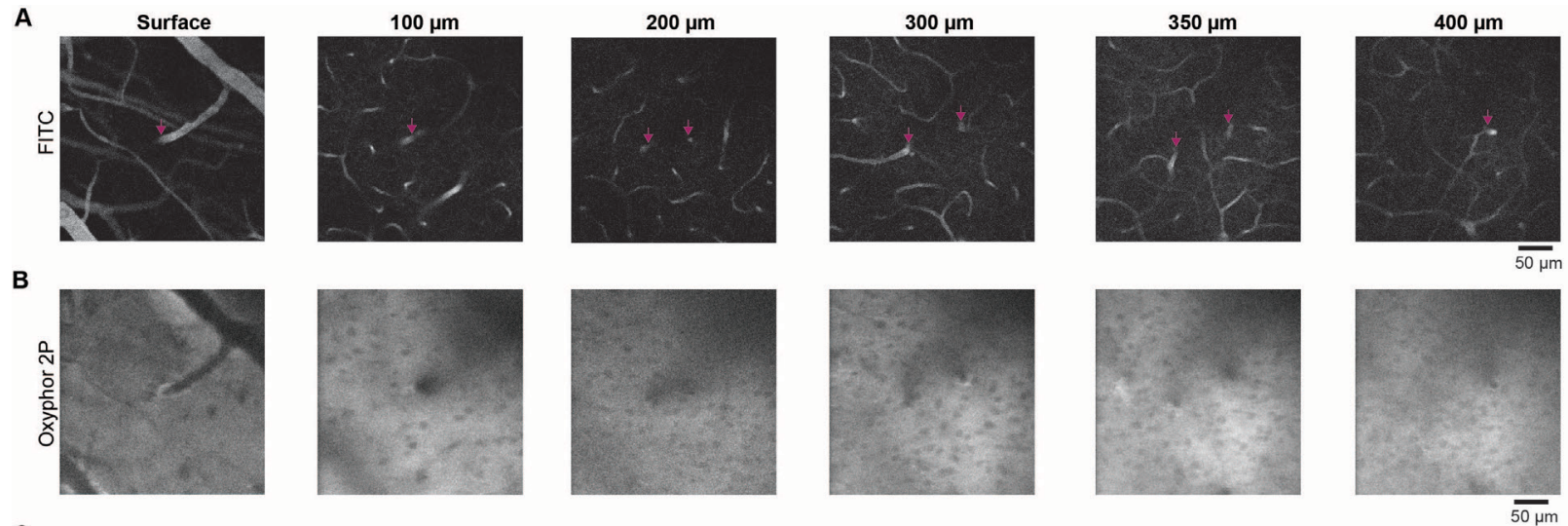

C
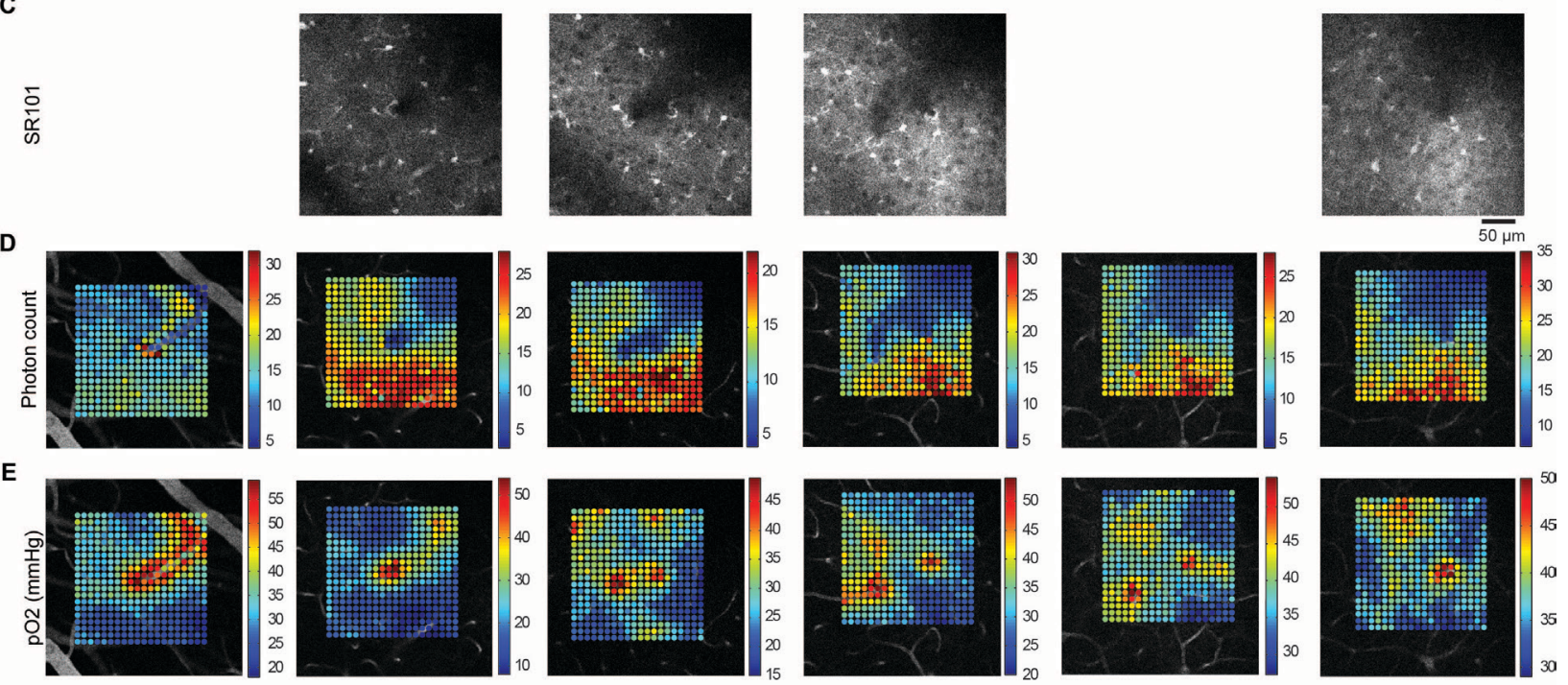
bioRxiv preprint doi: https://doi.org/10.1101/2021.10.13.464176; this version posted October 14,2021 . The copyright holder for this preprint (which was not certified by peer review) is the author/funder, who has granted bioRxiv a license to display the preprint in perpetuity. It is made available under aCC-BY 4.0 International license.

\section{Supplementary Figure 3}
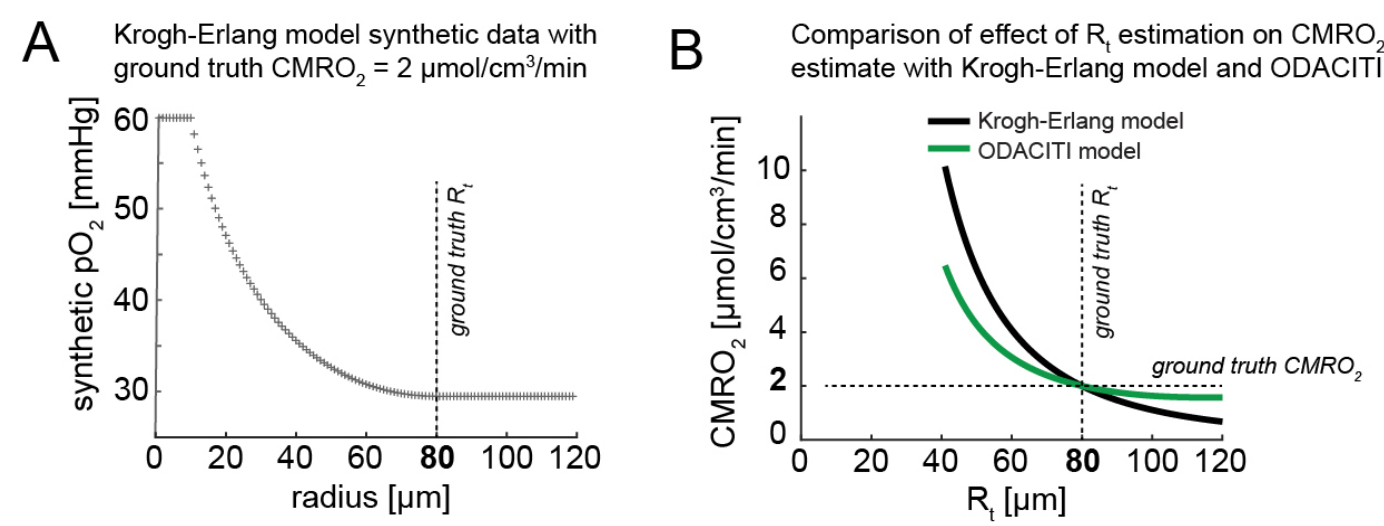


\section{Supplementary Figure 4}

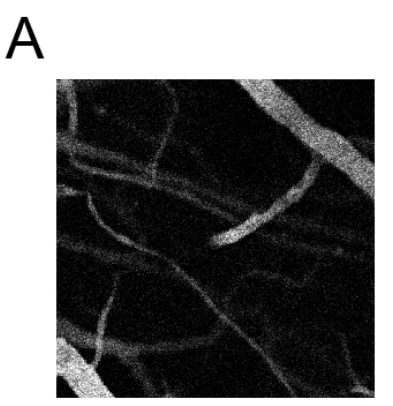

FITC

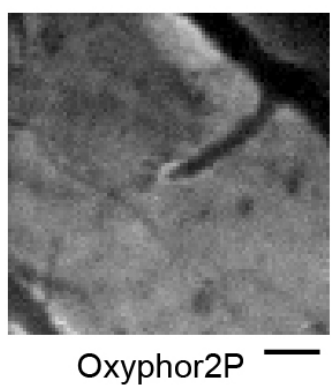

Oxyphor2P
B

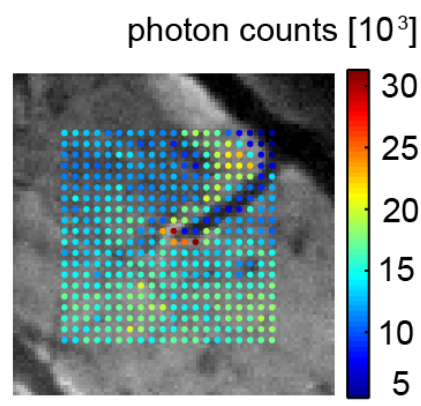

$\mathrm{pO}_{2}[\mathrm{mmHg}]$

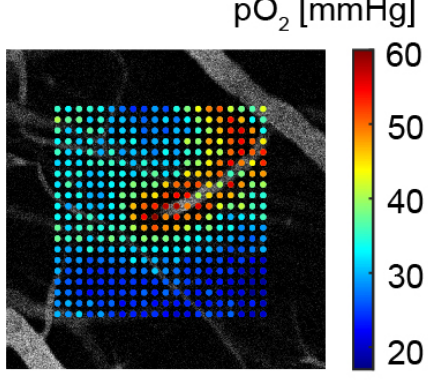

C

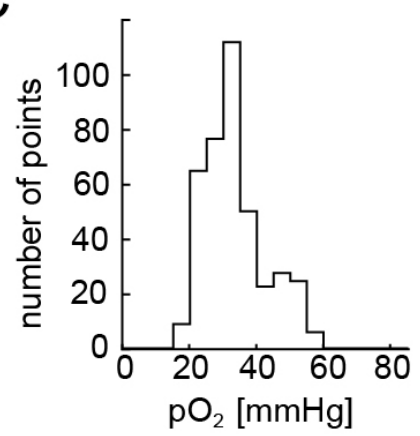

D

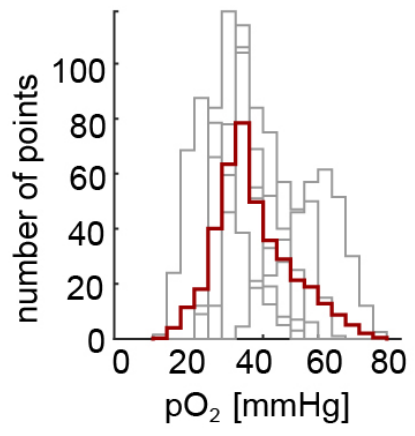


bioRxiv preprint doi: https://doi.org/10.1101/2021.10.13.464176; this version posted October 14,2021 . The copyright holder for this preprint (which was not certified by peer review) is the author/funder, who has granted bioRxiv a license to display the preprint in perpetuity. It is made available under aCC-BY 4.0 International license.

\section{Supplementary Figure 5}
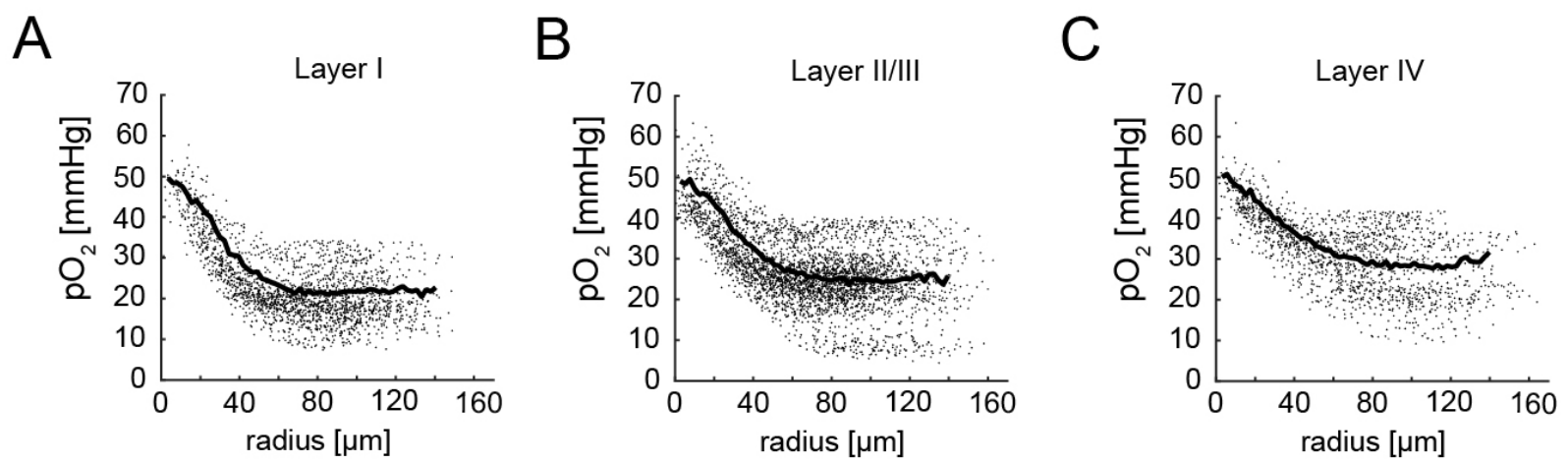
bioRxiv preprint doi: https://doi.org/10.1101/2021.10.13.464176; this version posted October 14, 2021. The copyright holder for this preprint (which was not certified by peer review) is the author/funder, who has granted bioRxiv a license to display the preprint in perpetuity. It is made available under aCC-BY 4.0 International license.

\section{Supplementary Figure 6}

A

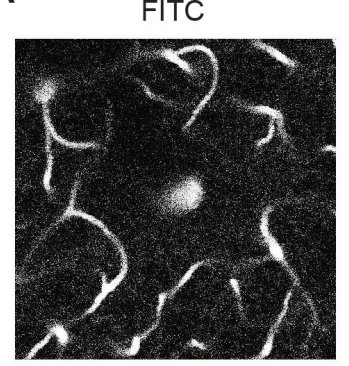

C

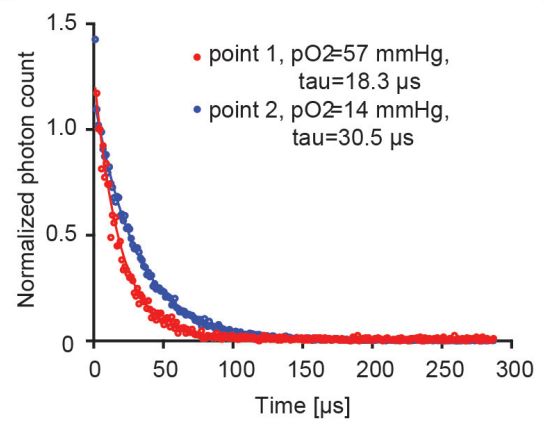

measurement grid

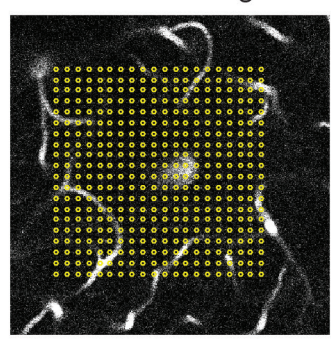

D

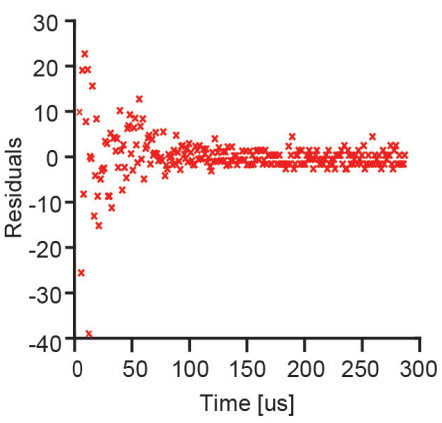

B

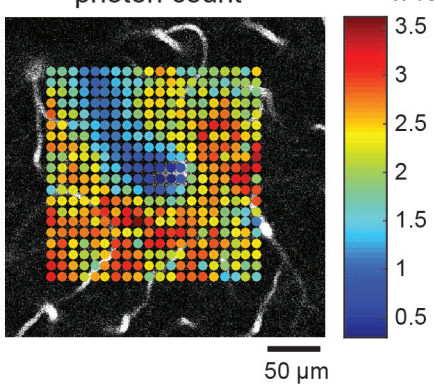

E

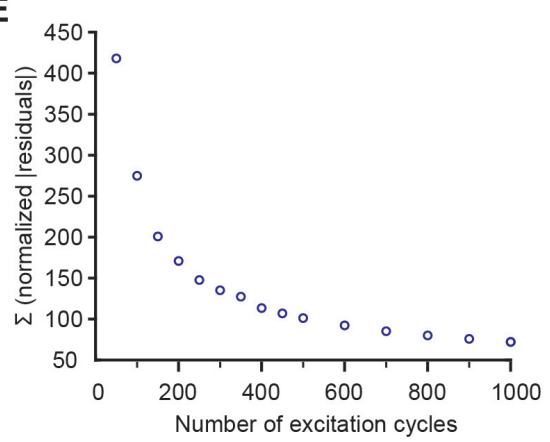

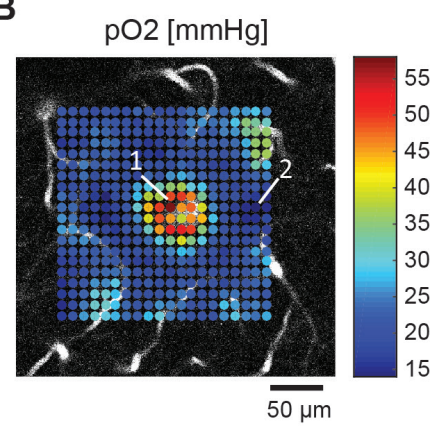

excitation cycles 